Check for updates

Cite this: Environ. Sci.: Processes Impacts, 2020, 22, 528

Received 19th December 2019

Accepted 12th February 2020

DOI: $10.1039 / c 9 e m 00592 \mathrm{~g}$

rsc.li/espi

\section{Quantifying the efficiency and selectivity of organohalide dechlorination by zerovalent iron $\uparrow$}

\author{
Feng He, (D) *a Li Gong, ${ }^{a}$ Dimin Fan, (D) ${ }^{b}$ Paul G. Tratnyek (DD *c \\ and Gregory V. Lowry iD d
}

The efficiency and selectivity of zerovalent iron-based treatments for organohalide contaminated groundwater can be quantified by accounting for redistribution of electrons derived from oxidation of $\mathrm{Fe}^{0}$. Several types of efficiency are reviewed, including (i) the efficiency of $\mathrm{Fe}(0)$ utilization, $\varepsilon_{\mathrm{Fe}(0)}$, (ii) the electron efficiency of target contaminant reduction, $\varepsilon_{\mathrm{e}}$, and (iii) the electron efficiency of natural reductant demand (NRD) involving $\mathrm{H}_{2} \mathrm{O}, \mathrm{O}_{2}$, and co-contaminants such as nitrate, $\varepsilon_{\mathrm{NRD}}$. Selectivity can then be calculated by using $\varepsilon_{\mathrm{e}} / \varepsilon_{\mathrm{NRD}}$. Of particular interest is $\varepsilon_{\mathrm{e}}$ and the key to its determination is measuring the total quantity of electrons provided by $\mathrm{Fe}^{0}$ oxidation, which can be based on either the loss of $\mathrm{Fe}(0)$, the formation of $\mathrm{Fe}\left({ }_{11}\right) / \mathrm{Fe}(\mathrm{II})$, or the composition of the total reaction products. Recently, many data have accumulated on $\varepsilon_{\mathrm{e}}$ for the treatment of various chlorinated solvents (esp. trichloroethylene, TCE) by zerovalent iron (ZVI), and analysis of these data shows that ZVI particle properties (e.g., stabilization with polymers, bimetallic modification, sulfidation, etc.) and other operational factors have variable effects on $\varepsilon_{\mathrm{e}}$. Of particular interest is that pre-exposure of ZVI to reduced sulfur species (i.e., sulfidation) consistently improves the $\varepsilon_{\mathrm{e}}$ of contaminant reduction, mainly by suppressing the reduction of water.

\section{Environmental significance}

The criteria used in the selection and optimization of water treatment processes include not only the rate and products of contaminant degradation, but also the efficiency with which material or energy inputs (e.g., amendment with zerovalent iron) result in changes in contaminant and other species concentrations. Reliable comparison between treatment systems, or the effects of operational variables on treatment performance, requires clear and consistent definitions for the quantification of various types of process efficiency and selectivity. This is illustrated for the treatment of organohalide contaminated groundwater with zerovalent iron, where the data are available to compare different definitions of efficiency and the benefits of various strategies for increasing the efficiency (e.g., sulfidation).

\section{Introduction}

In all but the simplest chemical reaction systems, there are alternative routes for reactant utilization and product formation, and accounting for these alternatives is often done in terms of "selectivity" and "efficiency" (or related concepts like the "branching ratio", "yield", and "capacity"). These concepts are general and therefore widespread across many areas of chemistry, but their definition and methods of application

${ }^{a}$ College of Environment, Zhejiang University of Technology, Hangzhou 310014, China. E-mail: fenghe@zjut.edu.cn; Tel: +86-571-88871509

${ }^{b}$ Geosyntec Consultants, 65 N Raymond Ave Suite 200, Pasadena, CA 91103, USA ${ }^{c}$ OHSU-PSU School of Public Health, Oregon Health \& Science University, 3181 SW Sam Jackson Park Road, Portland, OR 97239, USA. E-mail: tratnyek@ohsu.edu; Tel: +1 503-346-3431

${ }^{d}$ Department of Civil and Environmental Engineering, Carnegie-Mellon University, Pittsburg, PA 15213, USA

$\dagger$ Electronic supplementary information (ESI) available. See DOI: $10.1039 / \mathrm{c} 9 \mathrm{em} 00592 \mathrm{~g}$ usually have been treated as ad hoc and system-specific. This contributes to ambiguities and inconsistencies that can make comparisons between studies difficult. These challenges make it hard to generalize about the factors that control efficiency and selectivity, which probably has impeded progress towards the optimization of a variety of engineered chemical processes.

One system that exemplifies all of the above characteristics is the reduction of halogenated hydrocarbon contaminants in water using zerovalent iron (ZVI). This process is widely used for a variety of water treatment applications, most notably the remediation of groundwater contaminated with chlorinated solvents (e.g., trichloroethylene, TCE) by the application of granular, microscale, or nanoscale ZVI. ${ }^{1-5}$ Most aspects of this system have been studied extensively, ranging from the kinetics of specific contaminant reduction reactions to the effects of subsurface conditions on the overall remediation performance. ${ }^{6-8}$ There is also extensive literature on ZVI-based treatments for other contaminants of concern (COCs), especially metals and metalloid oxyanions (chromate, arsenate, 
pertechnetate, etc.) ${ }^{9-12}$ some of which address the efficiency and selectivity of those processes. ${ }^{13-18}$ Because the science and engineering of contaminant degradation, especially dechlorination, in the $\mathrm{Fe}$-water system are relatively mature, most current research is now focused on higher-level issues like the optimization of the process to maximize its efficiency for contaminant degradation (e.g., electron efficiency). ${ }^{19-21}$

Throughout this manuscript, the term "efficiency" is used in a precise technical sense (i.e., the relative quantity of inputs to outputs in a process ${ }^{22}$ ), rather than the common but casual and not entirely accurate use of the term as a synonym for the rate of contaminant removal (e.g., "removal efficiency"s and "degradation efficiency"23). Given the focus of this work on organohalide reduction by ZVI, the general definition of efficiency we use here is the relative quantity of electrons transferred from ZVI to each of the competing product formation reactions. Given that ZVI is a rather strong reductant that can drive redox reactions with a variety of natural oxidants, including water, other (co)-contaminants (esp. nitrate and heavy metals), and dissolved oxygen, efficiencies can also be defined for each individual process or for groups of processes such as reactions with all non-contaminant oxidants (i.e., natural reductant demand, NRD). All of these types of efficiencies correspond to Type II defined in a recent study ${ }^{20}$ and are the primary focus of this paper.

Additional types of efficiency arise because the ZVI used in groundwater remediation is a particulate material with variable composition and availability for reaction with solution species (e.g., nano-scale ZVI that may react fully while $\mathrm{mm}$-scale ZVI can passivate before all of the $\mathrm{Fe}(0)$ is oxidized). These efficiencies were classified as Type I in Qin et al. ${ }^{\mathbf{2 0}}$ and also are addressed in this study. Furthermore, it has been suggested that branching among pathways of degradation product formation (e.g., via hydrogenolysis $v s$. reductive elimination) might be classified as an efficiency (Type III in Qin $e t ~ a l .{ }^{20}$ ), but they are best expressed as product "yields", ${ }^{24-27}$ and are only addressed in this review as examples of "selectivity". Insofar as all of these types of efficiencies involve accounting for the redistribution of electrons with a system of redox reactions, they should be interrelated, and clarifying some of these relationships is a major goal of this work.

Throughout this manuscript, the term "selectivity" also is used in a precise technical sense (i.e., the relative quantity of two inputs or two outputs ${ }^{22}$ ). Therefore, in the context of this work, selectivity is usually used to refer to the ratio of efficiencies of two pathways of product formation from the reaction of ZVI with organohalides and NRDs, respectively. Here, organohalide dechlorination is the desired reaction whereas reduction of various NRDs is the main undesired reaction. For example, the reduction of water by ZVI to form hydrogen (i.e., hydrogen evolution reaction (HER)) is the most important undesired reaction output of ZVI because water is present at much higher concentration than contaminants and water cannot be exhausted. As a result, the selectivity of dechlorination over the HER can be poor for many types of ZVI. Another form of selectivity involves the relative rates of two parallel contaminant reduction reactions, which could be applicable to a mixture of chlorinated compounds. While ZVI may exhibit different selectivity for different organohalide contaminants, this selectivity among contaminants is not our focus because this review is mostly interested in considering dechlorination processes as a whole, which is distinguished from reduction of NRDs.

A fundamental issue that applies generally to the efficiencies and selectivities discussed below is the role of time. In a system like organohalide dehalogenation by ZVI, the contributing reactions proceed at different rates and these reactions can change system conditions that further alter reaction rates over time. The net effect of these time-dependent processes can cause changes in efficiencies as the process proceeds from beginning to end. ${ }^{28}$ Most studies have either avoided this issue or assumed that a relatively steady-state condition is reached by the end of experiments and efficiencies calculated at this point are comparable. ${ }^{20}$ The latter may be adequate for some purposes, but there are many possible reasons why this could give misleading results. However, there also are ways this issue can be turned into an advantage, such as in the systematic comparison of efficiencies obtained under halocarbon- $v s$. ZVIlimiting conditions ${ }^{29}$ which is discussed below.

All of the above general issues regarding the definition, quantification, and interpretation of electron efficiencies in the system of organohalide reduction by ZVI have received heightened attention in the last few years. This is the result of several factors, including (i) widespread recognition that the promised benefits of nano-scale ZVI could not be achieved without improving its efficiency and therefore longevity for abiotic reductive dechlorination in situ, (ii) discovery that the treatment of ZVI with reduced forms of sulfur (i.e., sulfidation) can significantly improve the efficiency of dechlorination by ZVI, and (iii) general advancement of this field of research such that more advanced process questions can be addressed. The efficiency implications of sulfidation are especially significant, and they have motivated much of the recent work on the efficiencies of water treatment processes involving ZVI, so this aspect is emphasized in the latter sections of this review. Overall, this review aims to present a systematic overview of past and current research on the efficiency and selectivity of ZVI for dechlorination by summarizing a broad range of topics including the fundamental terminology, quantitation approaches, environmental factors that affect efficiency, and natural and engineering enhancements of efficiency.

\section{Classification of efficiencies}

The overall relationship between types of efficiencies involved in contaminant degradation by ZVI is summarized in Fig. 1. The first type of efficiency to consider is the fraction of $\mathrm{Fe}(0)$ that is available for reaction in the time frame relevant for remediation (months to years). The fraction of $\mathrm{Fe}(0)$ associated with ZVI that is available for oxidation (by contaminants and non-target species combined) has been referred to as the "utilization ratio" or "efficiency of $\mathrm{Fe}(0)$ utilization". ${ }^{15,29}$ This quantity $\left(\varepsilon_{\mathrm{Fe}(0)}\right)$ is defined by eqn (1). 


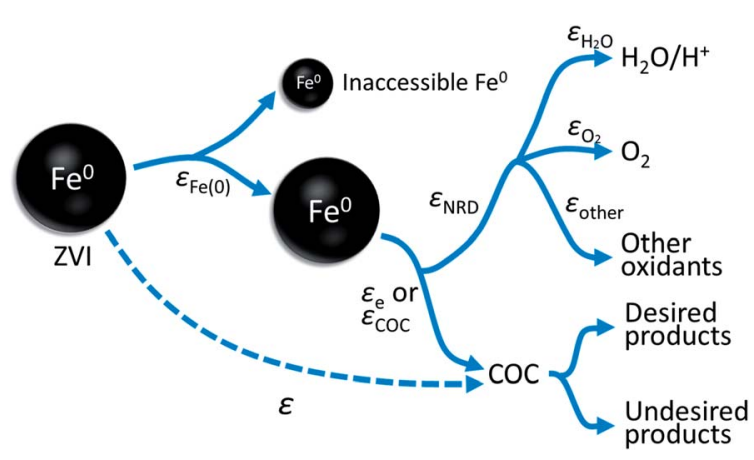

Fig. 1 Summary of the relationship between the particle efficiency $(\varepsilon)$, efficiency of $\mathrm{Fe}(0)$ utilization $\left(\varepsilon_{\mathrm{Fe}(0)}\right)$, electron efficiency $\left(\varepsilon_{\mathrm{e}}\right.$ or $\left.\mathrm{EE}\right)$ of contaminant reduction, and the electron efficiency of NRD (e.g., $\mathrm{H}_{2} \mathrm{O}$, $\mathrm{O}_{2}$, and other oxidants) reduction $\left(\varepsilon_{\mathrm{NRD}}\right)$. Earlier versions of this conceptual model can be found in Qin et al. ${ }^{15}$

$$
\varepsilon_{\mathrm{Fe}(0)}=\frac{M_{\mathrm{Fe}(0), \text { initial }}-M_{\mathrm{Fe}(0), \text { final }}}{M_{\mathrm{Fe}(0), \text { initial }}}
$$

where $M_{\mathrm{Fe}(0) \text {,initial }}$ and $M_{\mathrm{Fe}(0) \text {,final }}$ are the initial molar quantity of $\mathrm{Fe}^{0}$ and the final quantity of $\mathrm{Fe}^{0}$ at the end of the particle's reactive lifetime. In this case, particle lifetime is operationally defined by complete loss of reactivity for dechlorination, which differs from the endpoint used for some of the other efficiencies defined below. For larger ZVI particles, such as microscale ZVI (mZVI) or construction-grade ZVI, low $\varepsilon_{\mathrm{Fe}(0)}$ values should be common because accumulation of the iron oxide products of $\mathrm{Fe}(0)$ oxidation results in complete passivation before the $\mathrm{Fe}(0)$ at the particle core reacts.

The electrons released by accessible $\mathrm{Fe}(0)$ (as defined by $\left.\varepsilon_{\mathrm{Fe}(0)}\right)$ can be utilized to reduce the primary COC or the other oxidants such as $\mathrm{H}_{2} \mathrm{O}$, dissolved oxygen, nitrate, or non-target co-contaminants. The efficiency of electron utilization for contaminant reduction relative to all of the reduction reactions has been termed electron efficiency $\left(\varepsilon_{\mathrm{e}}\right.$ or $\mathrm{EE}$ ), whereas the electron efficiencies of reactions with $\mathrm{H}_{2} \mathrm{O}, \mathrm{O}_{2}$, and other oxidants can be expressed as $\varepsilon_{\mathrm{H}_{2} \mathrm{O}}, \varepsilon_{\mathrm{O}_{2}}$, and $\varepsilon_{\text {other }}$, respectively. The sum of efficiencies of reduction processes involving these non-target species that are responsible for natural reductant demand is defined here as $\varepsilon_{\mathrm{NRD}}$.

As indicated by Fig. 1, the overall efficiency with which ZVI reduces COCs - which was termed "particle efficiency $(\varepsilon)$ " by Liu et $a l .{ }^{30}$-is the product of $\mathrm{Fe}(0)$ utilization efficiency $\left(\varepsilon_{\mathrm{Fe}(0)}\right)$ and electron efficiency $\left(\varepsilon_{\mathrm{e}}\right)$ at the end of the particle reactive lifetime (i.e., $\varepsilon=\varepsilon_{\mathrm{Fe}(0)} \times \varepsilon_{\mathrm{e}}$ ). Therefore, if the $\mathrm{Fe}^{0}$ is fully consumed (i.e., $\left.\varepsilon_{\mathrm{Fe}(0)}=1\right)$, then $\varepsilon$ is equal to $\varepsilon_{e}$.

\section{Determination of electron efficiency $\left(\varepsilon_{\mathrm{e}}\right)$}

Electron efficiency $\left(\varepsilon_{\mathrm{e}}\right)$ is the fraction of total electrons from ZVI oxidation that are used in the reduction of COCs (in this review, dechlorination of organohalides). As shown in Fig. 1, and discussed further below, the branching between $\varepsilon_{\mathrm{e}}$ and $\varepsilon_{\mathrm{NRD}}$ reflects the competition between (and selectivity for) oxidants for the electrons donated by $\mathrm{Fe}^{0}$. It should be noted that, in some cases, this representation may not describe the actual reaction pathway or mechanism. For example, nZVI synthesized by the borohydride reduction method (i.e., $\mathrm{Fe} / \mathrm{B}$ ) was found to give a high electron efficiency (92\%), despite the formation of $\mathrm{H}_{2}$ gas from the reduction of water. ${ }^{30}$ This result was shown to arise because the $\mathrm{H}_{2}$ generated was used to dechlorinate TCE via hydrodehalogenation catalyzed by amorphous iron. ${ }^{31}$ This implies that the reduction of water and TCE dechlorination can involve sequential as well as parallel processes, even though the accounting used here (and in general, so far) treats all of the electrons used to reduce $\mathrm{H}_{2} \mathrm{O}$ as part of NRD. This simplification does not affect the approaches to the quantification of $\varepsilon_{\mathrm{e}}$ that are discussed below, although it must be considered when interpreting $\varepsilon_{\mathrm{e}}$ data as evidence regarding contaminant degradation mechanisms, as explained below.

The quantitative definition of $\varepsilon_{\mathrm{e}}$, which usually is expressed as a percentage, is given in eqn (2):

$$
\varepsilon_{\mathrm{e}}=\frac{N_{\mathrm{e}}}{N_{\mathrm{t}}}
$$

where $N_{\mathrm{e}}$ is the quantity of electrons utilized for the reduction of the COC and $N_{\mathrm{t}}$ is the total quantity of electrons provided by the oxidation of $\mathrm{Fe}(0)$. In this definition, each $N$ is described as a quantity of "electrons" because that is the most convenient and general basis for determining the extent of redox reactions. As noted above, however, this does not necessarily imply that these reactions occur (only) by electron transfer mechanisms, because various atom-transfer reactions can also contribute to redox reactions. In previous work, ${ }^{32}$ we have tried to address this issue by using the more general term "reducing equivalents", but that is not continued in this work for simplicity and consistency with the majority of other work on this topic. Also, for modified ZVI, and in particular sulfidated ZVI, electrons from iron sulfide are not considered here because the dechlorination of organohalides (e.g., TCE) by FeS is typically much slower than dechlorination by sulfidated ZVI.

\subsection{Quantification of $N_{\mathrm{e}}$}

To determine the quantity of electrons used in any contaminant reduction reaction from experimentally measured values of reactants and products, the corresponding redox halfreaction(s) must be specified. Using TCE dechlorination as an example, a generic half-reaction can be written as in eqn (3) (Liu et $a .^{30}$ ), which has been used in many studies with minor variations: $:^{29,33}$

$$
\mathrm{TCE}+n \mathrm{e}^{-}+m \mathrm{H}^{+}=\text {Products }+g \mathrm{Cl}^{-}
$$

However, several dechlorination products are possible (e.g., cisDCE, acetylene, ethane, etc.), which have different values of $n$, $m$, and $g$. With the quantification of all the reaction products, the overall value of $N_{\mathrm{e}}$ can be calculated using eqn (4). ${ }^{30}$

$$
N_{\mathrm{e}}=\sum_{i} n_{i} p_{i}
$$


where $n_{i}$ is the stoichiometry of product $i$ from the reduction of the target contaminant and $p_{i}$ is the molar quantity of that product.

\subsection{Quantification of $N_{\mathrm{t}}$}

The value of $N_{\mathrm{t}}$ (the total quantity of electrons provided by ZVI) can be determined from (i) the change in the reductant quantity (e.g., total $\mathrm{Fe}^{0}$ content of residual particles) or (ii) the change in the quantity of all reduction reaction products. The former approach can be performed in two ways: one based on the decrease in the $\mathrm{Fe}^{0}$ content, and the other is based on the increase in $\mathrm{Fe}(\mathrm{II}) / \mathrm{Fe}$ (III) species in both solid and aqueous phases. These two approaches are compared below.

3.2.1. $N_{\mathrm{t}}$ and $\varepsilon_{\mathrm{e}}$ calculation based on quantifying $\mathrm{Fe}^{\mathbf{0}}$ loss. In the first work on calculating the particle efficiency of nZVI for TCE dechlorination under anoxic conditions (Liu et al. ${ }^{30}$ ), a halfreaction for $\mathrm{Fe}(0)$ oxidation was assumed whereby 2 moles of $\mathrm{e}^{-}$ are donated by 1 mole of $\mathrm{Fe}^{0}$ (eqn (5)).

$$
\mathrm{Fe}^{0} \rightarrow \mathrm{Fe}^{2+}+2 \mathrm{e}^{-}
$$

Assuming that all of the $\mathrm{Fe}^{0}$ associated with the nZVI is oxidized, the theoretical quantity of electrons provided is twice the initial moles of $\mathrm{Fe}^{0}$ added $\left(N_{0}\right)$. Therefore, the particle efficiency was calculated by using eqn (6)

$$
\varepsilon=N_{\mathrm{e}} / 2 N_{0}
$$

Besides eqn (6), Liu et al. ${ }^{30}$ also proposed a method for measuring the quantity of residual $\mathrm{Fe}^{0}$ in $\mathrm{ZVI}$ at the end of the reaction $\left(N_{\mathrm{r}}\right)$. The $\mathrm{Fe}(0)$ content of the particles initially added to the reactor and from particles recovered from the reactor at the end of the reaction can be determined from the $\mathrm{H}_{2(\mathrm{~g})}$ produced by complete acid digestion using $\mathrm{HCl}$. Only $\mathrm{Fe}(0)$ is able to reduce $\mathrm{H}^{+} / \mathrm{H}_{2} \mathrm{O}$ to $\mathrm{H}_{2(\mathrm{~g})}\left(\mathrm{Fe}^{2+}, \mathrm{Fe}_{3} \mathrm{O}_{4}\right.$, and any other $\mathrm{Fe}$ oxides cannot reduce $\mathrm{H}^{+} / \mathrm{H}_{2} \mathrm{O}$ to $\mathrm{H}_{2(\mathrm{~g})}$ ), so each mole of $\mathrm{H}_{2(\mathrm{~g})}$ produced by the acid digestion is equivalent to a mole of $\mathrm{Fe}(0)$ that was present in the residual ZVI particles. Defined in this way, $N_{\mathrm{t}}$ is the difference between $N_{0}$ and $N_{\mathrm{r}}$.

Later, in a study performed under aerobic conditions, ${ }^{34}$ a similar approach was used to determine $N_{\mathrm{t}}$ for chromium and nitrobenzene reduction by ZVI, but it was assumed that 3 moles of $\mathrm{e}^{-}$were provided by 1 mole of $\mathrm{Fe}^{0}$, according to eqn (7).

$$
\mathrm{Fe}^{0} \rightarrow \mathrm{Fe}^{3+}+3 \mathrm{e}^{-}
$$
(8)

Under these conditions, $N_{\mathrm{t}}$ should be calculated using eqn

$$
N_{\mathrm{t}}=3\left(M_{\mathrm{Fe}(0), \text { initial }}-M_{\mathrm{Fe}(0), \text { unreacted }}\right)
$$

where $M_{\mathrm{Fe}(0) \text {,initial }}$ is the initial moles of $\mathrm{Fe}^{0}$ and $M_{\mathrm{Fe}(0) \text {, unreacted }}$ is the unreacted moles of $\mathrm{Fe}(0)$ at the end of the reaction. A similar approach to calculate $N_{\mathrm{t}}$ for TCE dechlorination by ZVI under anoxic conditions was taken by Schöftner et al. (2015). ${ }^{35}$ However, in that case, it was assumed that 2.5 moles of electrons were released per 1 mole of $\mathrm{Fe}^{0}$ oxidized (i.e., $n=2.5$ ).

$$
\mathrm{Fe}^{0} \rightarrow 0.5 \mathrm{Fe}^{2+}+0.5 \mathrm{Fe}^{3+}+2.5 \mathrm{e}^{-}
$$

This assumption was based on changes in the composition of iron hydroxides determined by Mössbauer spectroscopy.

The assumption about the number of electrons from $\mathrm{Fe}(0)$ that are available for the reaction will depend on the redox potential of the COC, and potentially the composition of the water. So in general, $\varepsilon_{\mathrm{e}}$ based on the change of $\mathrm{Fe}(0)$ can be expressed as:

$$
\varepsilon_{\mathrm{e}}=\frac{\sum_{i} n_{i} p_{i}}{x\left(M_{\mathrm{Fe}(0), \text { initial }}-M_{\mathrm{Fe}(0), \text { unreacted }}\right)}
$$

where $x$ represents the moles of electrons given by 1 mole of $\mathrm{Fe}^{0}$ for reduction processes.

The different methods summarized above highlight the need to accurately determine the reaction products formed and $x$, which depends on the fraction of $\mathrm{Fe}(\mathrm{II})$ or $\mathrm{Fe}(\mathrm{III})$ formed from $\mathrm{Fe}^{0}$ oxidation. The transformation of $\mathrm{Fe}^{0}$ varies with experimental conditions (e.g., aerobic vs. anoxic) and the contaminant type (especially, whether reducible by $\mathrm{Fe}(\mathrm{II})$ without $\mathrm{Fe}(0)$; e.g., $\mathrm{CCl}_{4}$ ). In addition, in many cases the iron oxides present include a diverse and dynamic mixture of phases with variable reactivity. ${ }^{36}$ Therefore, accurate determination of $x$ requires measurement of $\mathrm{Fe}(\mathrm{II})$ and $\mathrm{Fe}$ (III) species in both aqueous and solid phases.

3.2.2. $N_{\mathrm{t}}$ and $\varepsilon_{\mathrm{e}}$ calculation from $\mathrm{Fe}(\mathrm{II}) / \mathrm{Fe}(\mathrm{III})$ measurements. If accurate measurements of $\mathrm{Fe}$ (II) and $\mathrm{Fe}$ (III) in the iron oxidation products are available, they can be used to calculate $N_{\mathrm{t}}$ from an alternative expression derived from eqn (5) and (7):

$$
\begin{aligned}
N_{\mathrm{t}}=2\left(M_{\mathrm{Fe}(\mathrm{II}), \text { end }}-M_{\mathrm{Fe}(\mathrm{II}), \text { initial }}\right) & \\
& +3\left(M_{\mathrm{Fe}(\mathrm{III}), \text { end }}-M_{\mathrm{Fe}(\mathrm{III}), \text { initial }}\right)
\end{aligned}
$$

where $M_{\mathrm{Fe}(\mathrm{II}), \text { end }}$ and $M_{\mathrm{Fe}(\mathrm{III}) \text {,end }}$ are the total moles of $\mathrm{Fe}(\mathrm{II})$ and $\mathrm{Fe}(\mathrm{III})$ at the end of the reaction, respectively, and $M_{\mathrm{Fe}(\mathrm{II}) \text {,initial }}$ and $M_{\mathrm{Fe}(\mathrm{III}) \text {,initial }}$ are the initial moles of $\mathrm{Fe}(\mathrm{II})$ and $\mathrm{Fe}(\mathrm{III})$ contained in ZVI. If the initial moles of Fe(II) and Fe(III) are negligible (i.e., ZVI particles with negligible surface oxide), then the calculation of $N_{\mathrm{t}}$ can be simplified to

$$
N_{\mathrm{t}}=2 M_{\mathrm{Fe}(\mathrm{II})}+3 M_{\mathrm{Fe}(\mathrm{III})}
$$

where $M_{\mathrm{Fe}(\mathrm{II})}$ and $M_{\mathrm{Fe}(\mathrm{III})}$ are the total moles of $\mathrm{Fe}(\mathrm{II})$ and $\mathrm{Fe}(\mathrm{III})$, respectively, in both aqueous and solid phases at the end of reaction.

In general, the electron efficiency can therefore be determined from measuring only the reaction products from organohalide reduction, along with the change in both $\mathrm{Fe}$ (II) and $\mathrm{Fe}(\mathrm{III})$ containing species in the system using eqn (13).

$$
\varepsilon_{\mathrm{e}}=\frac{\sum_{i} n_{i} p_{i}}{2\left(M_{\mathrm{Fe}(\mathrm{II}), \text { end }}-M_{\mathrm{Fe}(\mathrm{II}), \text { initial }}\right)+3\left(M_{\mathrm{Fe}(\mathrm{III}), \text { end }}-M_{\mathrm{Fe}(\mathrm{III}), \text { initial }}\right)}
$$

When the calculation of $N_{\mathrm{t}}$ based on the changes of Fe(II) and $\mathrm{Fe}(\mathrm{III})$ after a reduction reaction was first proposed, $\mathrm{Fe}$ (II) and 
$\mathrm{Fe}(\mathrm{III})$ in the aqueous phase were determined directly. ${ }^{34}$ For this, all of the iron phases were dissolved by acidification and analyzed with standard spectrophotometric methods under anoxic conditions. It was assumed that all of the unreacted $\mathrm{Fe}^{0}$ dissolved as Fe(II) during this process. Nonetheless, it is difficult to distinguish how much $\mathrm{Fe}(\mathrm{II})$ was generated from the dissolution of oxides containing $\mathrm{Fe}(\mathrm{II})$ and how much was from $\mathrm{Fe}^{0}$, so this method has not been widely adopted.

The main alternatives to dissolution and spectrophotometry for the speciation of iron are direct spectroscopic methods, mainly X-ray absorption fine structure (XAFS) analysis and Mössbauer spectroscopy. For example, a recent study used XAFS to quantify $\mathrm{Fe}$ (II) and $\mathrm{Fe}(\mathrm{III})$ in ZVI-derived solids after reaction with $\mathrm{Se}(\mathrm{Iv}),{ }^{15}$ from which efficiencies were calculated. The main advantage of these direct spectroscopy methods is that they can identify and quantify specific iron mineral phases. However, for all the types of efficiencies defined above, this level of iron speciation detail is not necessary. The main disadvantage of XAFS is that it can only detect phases present at greater than about $5 \%$, and the accuracy of quantification of most phases is only about $\pm 10 \%$. Moreover, distinguishing between magnetite (a mixed $\mathrm{Fe}(\mathrm{II}) / \mathrm{Fe}$ (II) phase) and maghemite (an Fe(III) phase with a similar Fe coordination environment) using EXAFS is difficult. ${ }^{36}$ Mössbauer spectroscopy can be helpful in distinguishing between these phases, so a combination of these methods could prove powerful if sufficient oxide is present. In cases where there is insufficient oxidation of $\mathrm{ZVI}$-due to anoxic conditions, or contaminant degradation is so rapid that reaction times are too short for oxidation by NRD to produce significant oxide $-N_{\mathrm{t}}$ can only be accurately determined by back-calculation from all measured reaction products.

3.2.3. $N_{\mathrm{t}}$ and $\varepsilon_{\mathrm{e}}$ calculation based on quantifying all reaction products. The calculation of $\varepsilon_{\mathrm{e}}$ can be based on the quantification of all reaction products, including those from the target contaminant and side reactions. Complete quantification of dechlorination products was first used to determine $N_{\mathrm{e}}$ by Liu et al. (2005), ${ }^{30}$ using TCE as the COC and two forms of nZVI as the reductant. More recently, the approach of quantifying all reaction products has been developed to calculate $\varepsilon_{\mathrm{e}}$ for TCE dechlorination by mechanochemically sulfidated ZVI (S$\left.\mathrm{mZVI}^{\mathrm{bm}}\right) .{ }^{29}$ Since the electron acceptors in this anoxic system included only TCE and $\mathrm{H}_{2} \mathrm{O}, N_{\mathrm{t}}$ could be calculated as the sum of the electrons used for reducing TCE (i.e., eqn (4)) and the electrons used for reducing $\mathrm{H}_{2} \mathrm{O}$ using eqn (14):

$$
N_{\mathrm{t}}=\sum_{i} n_{i} p_{i}+2 M_{\mathrm{H}_{2}}
$$

where $M_{\mathrm{H}_{2}}$ is the molar quantity of $\mathrm{H}_{2}$ produced during the TCE dechlorination. Note that each mol of $\mathrm{H}_{2}$ formed from $\mathrm{H}^{+} / \mathrm{H}_{2} \mathrm{O}$ requires 2 moles of electrons $\left(\mathrm{H}^{+}+2 \mathrm{e}^{-} \rightarrow \mathrm{H}_{2(\mathrm{~g})}\right)$. One requirement for using this approach is that the reactor must allow headspace measurement of $\mathrm{H}_{2}$. If other oxidants such as nitrate or co-contaminants are present and their reaction products (e.g., $p_{j}$ ) are measurable, then the electron consumption for these oxidants should also be considered using eqn (15), ${ }^{20}$

$$
N_{\mathrm{t}}=\sum_{i} n_{i} p_{i}+\sum_{j} n_{j} p_{j}+2 M_{\mathrm{H}_{2}}
$$

where $n_{j}$ is the stoichiometry of the formed product $j$ from reduction of a non-target contaminant or oxidant, and $p_{j}$ is the molar quantity of that product. With this approach, $\varepsilon_{\mathrm{e}}$ can be calculated using eqn (16).

$$
\varepsilon_{\mathrm{e}}=\frac{\sum_{i} n_{i} p_{i}}{\sum_{i} n_{i} p_{i}+\sum_{j} n_{j} p_{j}+2 M_{\mathrm{H}_{2}}}
$$

Similarly, the electron efficiency for the HER can be written as:

$$
\varepsilon_{\mathrm{H}_{2}}=\frac{2 M_{\mathrm{H}_{2}}}{\sum_{i} n_{i} p_{i}+\sum_{j} n_{j} p_{j}+2 M_{\mathrm{H}_{2}}}
$$

The electron efficiency for reduction involving cocontaminants or other oxidants that contribute to NRD can be written with similar equations, for example as was done for nitrate in competition with $\mathrm{NDMA}^{\mathbf{2 0}}$ and chromate against TCE. ${ }^{37}$

The approach represented by eqn (16) has several advantages over the approaches that rely on solid phase characterization. First, this approach requires only solution phase measurements, which are generally more accessible and sensitive than specialized instrumentation requiring significant mineralogical transformation for detection. Secondly, the solution-based approach also allows repeated determination of $\varepsilon_{\mathrm{e}}$ over the reaction course without the need for ZVI to reach the end of its reaction or sacrificing reactors for recovering and characterizing solid iron phases. This provides an opportunity to evaluate $\varepsilon_{\mathrm{e}}$ as a function of reaction time. Due to all of these advantages, this product-based approach is the most frequently adopted to calculate electron efficiency. ${ }^{\mathbf{2 0 1 2 1 3 7 - 4 0}}$ Nevertheless, this method still has shortcomings. The most significant one is that if oxygen is present (i.e., oxic conditions), the method is less useful because the products of reaction with oxygen, such as oxyhydroxide precipitates and $\mathrm{OH}^{-}$, are not easily quantified.

\subsection{The linkage between different $\varepsilon_{\mathrm{e}}$ quantification approaches}

It is noteworthy that the three approaches discussed above for calculating $N_{\mathrm{t}}$ and $\varepsilon_{\mathrm{e}}$ are related and the results should be comparable under certain conditions. For example, under excess iron and anoxic conditions, the $\varepsilon_{\mathrm{e}}$ for dechlorination of TCE by nanoscale Fe-Pd and Fe-Ni was determined to be $99.9 \%$ and $69 \%$, respectively, based on the approach of quantifying all reaction products. ${ }^{39}$ However, if $N_{\mathrm{t}}$ was calculated based on the change of $\mathrm{Fe}^{0}$ assuming $n=2$, then $\varepsilon_{\mathrm{e}}$ would be $93 \%$ and $72 \%$, which are similar to the $\varepsilon_{\mathrm{e}}$ calculated by quantifying reaction products. This also suggests that further oxidation of $\mathrm{Fe}(\mathrm{II})$ to $\mathrm{Fe}(\mathrm{III})$ by oxidants such as TCE was minimal. 


\section{Factors affecting the electron efficiency of dechlorination by ZVI}

The three types of electron efficiencies described above are affected by factors that can be intrinsic or extrinsic. The intrinsic factors relate mainly to the physical and chemical properties of ZVI (e.g., particle size, crystallinity, surface area, hydrophobicity, or dopants), whereas the extrinsic factors include many environmental system variables, such as water $\mathrm{pH}$, target contaminant concentration, and the presence of nontarget reducible co-contaminants. These effects on $\varepsilon_{\mathrm{e}}$ can be further complicated by changes in the system over time as reactions proceed ( $c f$. Section 4.2.4). To provide a quantitative basis for the comparison and interpretation of the how particle properties and environmental conditions affect the efficiency, we have summarized the available data in Table S1† and Fig. 2. The figure illustrates some of the effects that these factors have on efficiency, and these are discussed further below.

\subsection{Effect of ZVI particle properties on electron efficiency}

Modification of the ZVI composition or surface can improve treatment performance. Most recent work on this has focused on nanoscale ZVI, which has included: (i) bimetallic modification to enhance reactivity, (ii) stabilization with polymer coatings or carbon supports to enhance particle stability and mobility in the subsurface, and (iii) sulfidation to increase $\varepsilon_{\mathrm{e}}$. The substantial practical benefits of sulfidation have motivated most of the new work on the efficiency of ZVI-based treatment processes, but the resulting advances are applicable to the (mostly earlier) work on the first two phases noted above.

4.1.1. Effect of bimetallic modification. The combination of ZVI with catalytic noble metals was the first intensively studied approach to increase the reaction rate and to broaden the types of contaminants amenable to reduction. ${ }^{41-46}$ These bimetallic materials are easily prepared by reductive precipitation of metals (e.g., $\mathrm{Pd}, \mathrm{Pt}, \mathrm{Ni}, \mathrm{Ag}$, or $\mathrm{Cu}$ ) with more anodic reduction potentials than $\mathrm{Fe}(0)$. Bimetallic modification usually results in a thin discontinuous layer of noble metal "islands" on the ZVI surface. ${ }^{47}$ This layer of deposited metal can enhance the reactivity of bimetallic particles by (i) galvanic coupling between the two metals, (ii) hydrodehalogenation catalyzed by the noble metal, ${ }^{48}$ (iii) conductive islands in the oxide layer, and/or (iv) a cathodic shift in corrosion potentials $;{ }^{42}$ although only catalytic hydrodehalogenation and galvanic coupling are commonly considered.

While there has been abundant evidence that bimetallic modification of ZVI can accelerate the rates of both dechlorination and hydrogen evolution, it was not as clear whether bimetallic modification enhances the electron efficiency. One recent study, ${ }^{39}$ found that the $\varepsilon_{\mathrm{e}}$ for TCE dechlorination by nanoscale $\mathrm{Fe}-\mathrm{Pd}, \mathrm{Fe}-\mathrm{Ni}, \mathrm{Fe}-\mathrm{Cu}, \mathrm{Fe}-\mathrm{Ag}$, and nZVI with excess TCE ranged from $100 \%$ to $\sim 2 \%$, following the order of $\mathrm{Pd}>\mathrm{Ni}$ $\gg \mathrm{Cu}, \mathrm{Ag}$ and unmodified ZVI. However, the rate of hydrogen evolution in the absence of TCE followed a similar order (i.e., Pd $>\mathrm{Ni}>\mathrm{Ag}>\mathrm{Cu}>$ unmodified), indicating that the bimetallic compounds also increase reactivity with water. The higher $\varepsilon_{\mathrm{e}}$ for $\mathrm{Pd}$ and $\mathrm{Ni}$, despite the higher hydrogen evolution rate, presumably is because $\mathrm{Pd}$ and $\mathrm{Ni}$ can catalyze hydrodechlorination by the $\mathrm{H}_{2}$ produced from anoxic corrosion of $\mathrm{Fe}(0)$. For $\mathrm{Ag}$ and $\mathrm{Cu}$, which do not dissociate $\mathrm{H}_{2}$ and use it for hydrodechlorination, the $\varepsilon_{\mathrm{e}}$ was comparable to that of nZVI (Fig. 2, red markers in the lower-left corner). However, it should be noted that the high $\varepsilon_{\mathrm{e}}$ of $\mathrm{Fe}-\mathrm{Pd}$ and $\mathrm{Fe}-\mathrm{Ni}$ measured in the laboratory is not consistent with the field performance of bimetallic nZVI observed in several pilot-scale field demonstration studies, where source treatment using Fe-Pd nanoparticles showed little or no persistence of abiotic dechlorination. ${ }^{49,50}$ This may be due to a combination of (i) catalyst deactivation, (ii) the generated $\mathrm{H}_{2}$ diffusing away from the ZVI surface, or (iii) mass transfer limitations of TCE. For example, a laboratory study showed that Pd-nZVI, after $24 \mathrm{~h}$ exposure to water without TCE, exhibited significant surface

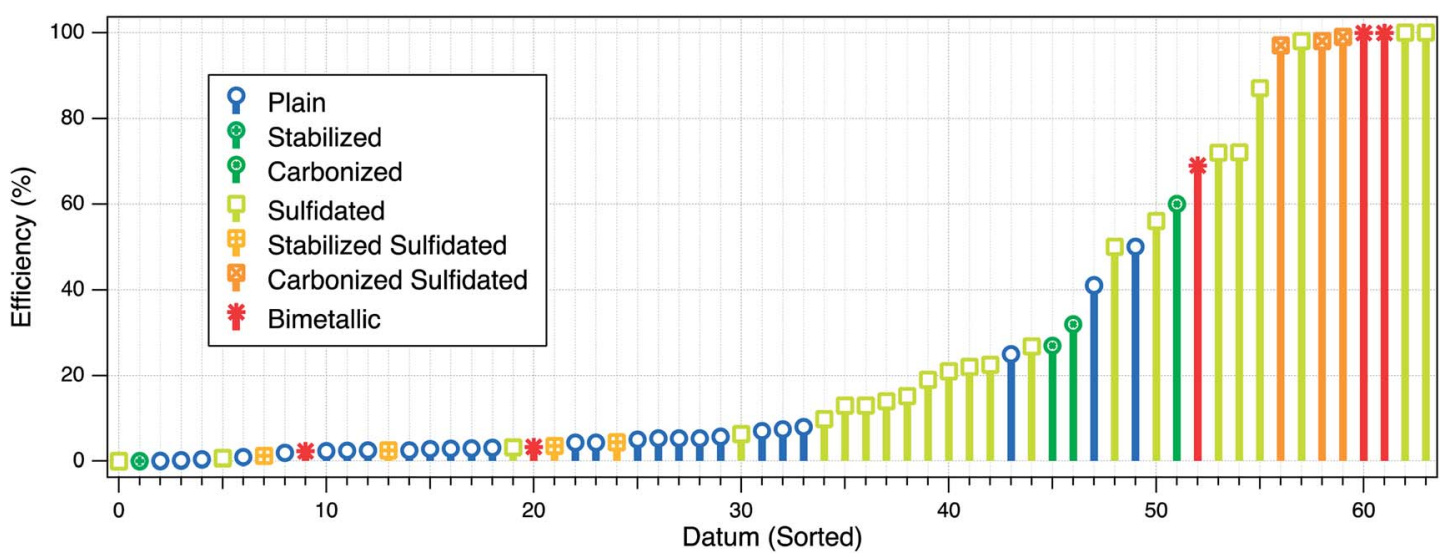

Fig. 2 Summary of published efficiency data from studies of contaminant reduction by ZVI. For each experiment, all types of efficiencies that were reported are plotted at one position on the datum axis, which was sorted by increasing value of $\varepsilon_{\mathrm{e}}$. Some of the main factors that affect the efficiency are represented in the figure by the marker type and color. The data and meta-data compiled for this analysis are given in Table S1 of the ESI.† 
oxidation that buried the Pd catalyst, resulting in a significant loss of dechlorination reactivity. ${ }^{51}$

4.1.2. Effect of stabilization by polymer coatings. Polymers and surfactants such as carboxymethyl cellulose (CMC) have been adsorbed onto nZVI surfaces to limit agglomeration and enhance particle mobility in porous media. ${ }^{3,52}$ These polymer coatings provide steric or electrosteric repulsive forces to counter the intraparticle magnetic attraction. ${ }^{53}$ Limiting the agglomeration of the particles can provide more surface area and enhance their reactivity, but coating reactive surfaces with unreactive organic matter tends to be passivating in general, ${ }^{54}$ so it is not clear how the adsorption of polymers onto the particle surfaces will affect the efficiency of specific reduction reactions, or the selectivity among them. This effect will depend on how the adsorbed polymer affects reactivity with the target contaminant relative to non-target constituents, e.g. water. Both Saleh et al. (2007) $)^{55}$ and Phenrat et al. (2009) ${ }^{56}$ showed that adsorbed polymers on nZVI lowered the rate of TCE relative to the unmodified particles. However, the adsorbed polymers did not decrease the rate of hydrogen evolution (unpublished data). A more recent study reported that CMC stabilization of nZVI decreased $\varepsilon_{\mathrm{e}}$ for TCE by about 15 -fold $(0.43 \%$ to $0.03 \%)$ for $\mathrm{nZVI}$ and 5 -fold $(13 \%$ to $3.5 \%)$ for S-nZVI (at a $\mathrm{S} / \mathrm{Fe}$ molar ratio $=0.05) .{ }^{57}$ These results suggest that modifying nZVI with polymers like CMC, poly(styrene sulfonate) (PSS), and polyaspartate (PAP) tends to decrease $\varepsilon_{\mathrm{e}}$ for organohalide reduction, but this has not been systematically evaluated.

Natural organic matter (NOM) is a ubiquitous macromolecule in the environment, with well-known effects on the stability of suspended colloids, including nZVI. ${ }^{58}$ Similar to adsorbed synthetic polymers, the adsorption of NOM usually decreases the rates of contaminant reduction by ZVI. ${ }^{54,59}$ One study comparing nZVI and S-nZVI found that NOM had a similar effect on their reactivity with TCE: with a decrease in the TCE degradation rate constant by $60 \%$ and $78 \%$, respectively, at a relatively high concentration $\left(200 \mathrm{mg} \mathrm{C} \mathrm{L}^{-1}\right)$ of Suwanee River humic acid. ${ }^{60}$ The effect of NOM on hydrogen evolution by ZVI does not appear to have been studied to date, and there also does not appear to have been any work that specifically addresses the efficiency or selectivity effects of NOM on ZVI reactivity. This is a potentially important data gap that should be filled by future research.

4.1.3. Effect of sulfidation. Current research on the modification of ZVI for enhancing treatment efficiency has largely shifted to incorporation of reduced sulfur by natural or engineering sulfidation processes. ${ }^{1,61-64}$ While sulfidation can improve the rates of contaminant degradation by ZVI and promote dehalogenation reactions not typically observed for $\mathrm{ZVI}$ (e.g. defluorination), ${ }^{65}$ the main benefit of sulfidation is the suppression of the reduction of water by ZVI, thereby vastly increasing the selectivity of ZVI for contaminant degradation and overall electron efficiency of the material. ${ }^{66,67}$ To date, research on sulfidation of ZVI has mostly focused on nZVI, because its utility is most enhanced by sulfidation. More recently, the benefits of sulfidation for microscale ZVI (mZVI) have also been demonstrated. ${ }^{29}$
Sulfidation of ZVI can occur after or during the formation of the particles, which results in materials that differ in important ways. ${ }^{1}$ If sulfidation involves exposing already formed ZVI to reduced sulfur (such as in a permeable reactive barrier of conventional ZVI where the in situ biogeochemistry is sulfidic or when a commercial sulfidated product is prepared exposing conventional ZVI to dithionite), the result is the formation of an $\mathrm{FeS}_{x}$ shell on the particles. ${ }^{40}$ On the other hand, if the sulfur is present during particle formation, it is incorporated into the structure of the material to form an $\mathrm{Fe}(0)-\mathrm{FeS}$ composite. ${ }^{1}$ The operational conditions under which sulfidation is conducted and the amount of sulfur incorporated into the material influence the reactivity of S-ZVI, ${ }^{1,33}$ including its electron efficiency. It is important to note that not all of the added $\mathrm{S}$ in the synthesis procedure is incorporated into the sulfidized particles, and this is especially true for nZVI particles that are sulfidized after the nZVI is already formed, where less than $8 \%$ of the dosed sulfur was incorporated into the particles. ${ }^{33}$ As shown in Fig. 3A, the effect of the $\mathrm{S} / \mathrm{Fe}$ ratio on $\varepsilon_{\mathrm{e}}$ varies with the type of nZVI (e.g., polymer coated or not). The data for S-nZVI suggest a bimodal dependence of $\varepsilon_{\mathrm{e}}$ on the $\mathrm{S} / \mathrm{Fe}$ ratio (with a peak at $\mathrm{S} / \mathrm{Fe}=0.1$ ), whereas $\varepsilon_{\mathrm{e}}$ for S-CMC-nZVI increases monotonically with the $\mathrm{S} /$ $\mathrm{Fe}$ ratio. The resulting $\mathrm{FeS}_{x}$ materials are likely complex mixtures of zerovalent iron and different $\mathrm{Fe}$-sulfide phases depending on the amount of incorporated sulfur. The hydrophobicity of the surface of materials can also change depending on the sulfidation method or amount of incorporated sulfur. Both hydrophobicity and sulfur speciation in the particles can affect the relative reactivity with COCs and water and therefore can affect $\varepsilon_{\mathrm{e}}$. As a result of these uncertainties, it is currently difficult to predict how sulfur incorporation and polymer adsorption will affect $\varepsilon_{\mathrm{e}}$. In addition to the $\mathrm{S} / \mathrm{Fe}$ ratio, the sulfidation time also affects $\varepsilon_{\mathrm{e}}$ as shown in Fig. 3B. It has been recently shown that both the $\mathrm{S} / \mathrm{Fe}$ ratio and the sulfidation time also affect the morphology of S-nZVI, which in turn changes the reactivity and efficiency of S-nZVI for dechlorination..$^{40}$

Regardless of sulfidation conditions, the resulting materials generally evolve much less hydrogen from corrosion by water, but dechlorinate TCE at rates comparable to unsulfidated ZVI, ${ }^{68}$ so the net result is consistently and significantly improved $\varepsilon_{\mathrm{e}}$. This conclusion is demonstrated in Fig. 4, which summarizes all the available $\varepsilon_{\mathrm{e}}$ data for pairs of experiments done with and without sulfidation under otherwise comparable conditions. The figure is plotted in the $\pm R$ format that we have used in several recent studies. ${ }^{\mathbf{8}, 69}$ In this case, all of the $\varepsilon_{\mathrm{e}}$ data are plotted on $\pm R$ contours representing 5 - to 50 -fold increases in $\varepsilon_{\mathrm{e}}$ with sulfidation. More specifically, Fig. 4 shows that the benefit of sulfidation is greatest for CMC-nZVI, which presumably is because this material has exceptionally higher reactivity with water (due to its very small particle size and exposed surface area). ${ }^{57}$ Sulfidation of CMC-nZVI results in effectively complete inhibition of the HER, which allows high rates of TCE dechlorination to persist for more than a month..$^{40}$ Sulfidation also decreased the reaction of nZVI with competing oxidants that may be present in the water, e.g. nitrate. ${ }^{20,40}$

The greater selectivity of the material for TCE over nitrate or water has been attributed to the replacement of $\mathrm{Fe} / \mathrm{FeO}$ surface 

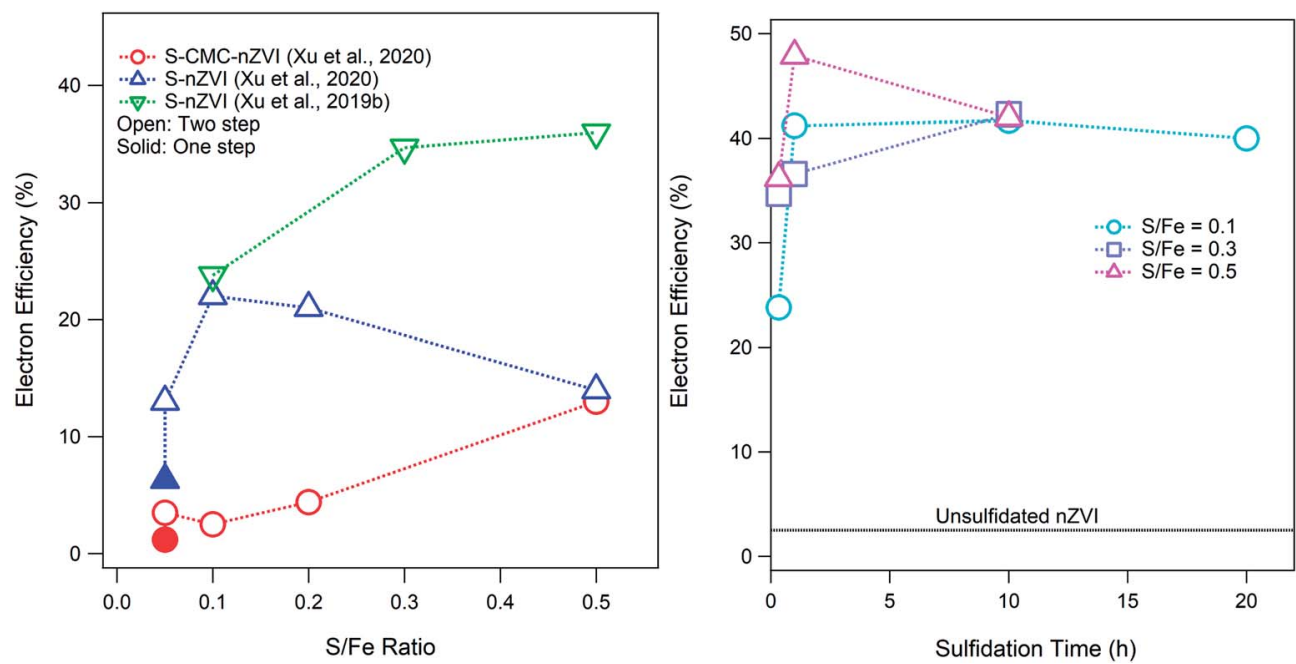

Fig. 3 (A) Effect of the S/Fe ratio on the electron efficiency of S-nZVI synthesized by two-step (i.e., post-synthesis) sulfidation (exposure time = 20 or $30 \mathrm{~min}$ ) compared with that of S-nZVI synthesized by a one-step method. (B) Effects of sulfidation time on the electron efficiency of postsynthesis S-nZVI. Data in (B) from Xu et al. ${ }^{33}$

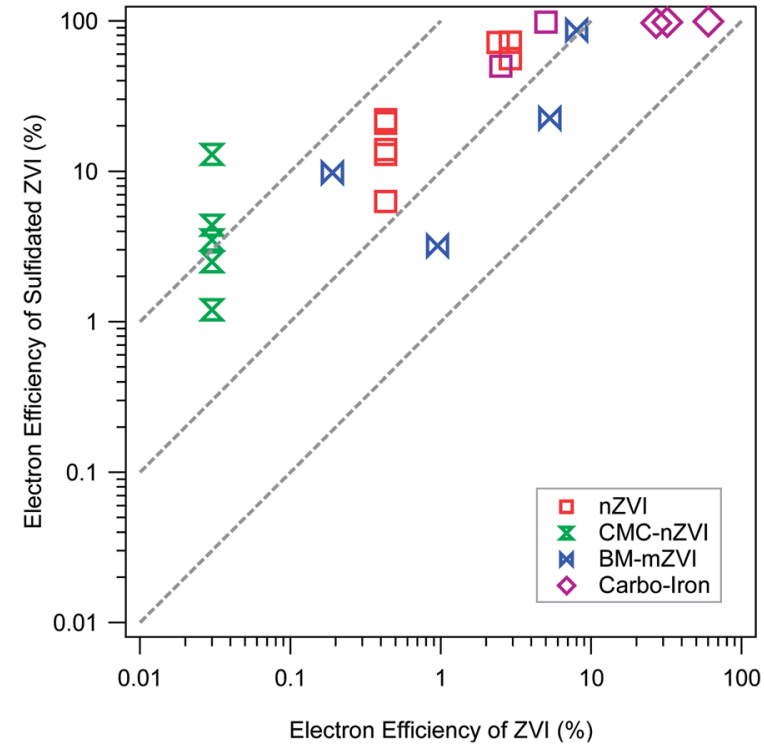

Fig. 4 Comparison of electron efficiencies $\left(\varepsilon_{\mathrm{e}}\right)$ for TCE reduction by $Z V I$ with ( $y$-axis) and without ( $x$-axis) sulfidation. Types of $Z V I$ are distinguished by the marker type and color. Data and experimental details are given in Table S1. $\dagger$

sites with $\mathrm{FeS},{ }^{20}$ which have different electronic and steric properties. The latter difference is evident in the greater hydrophobicity of S-nZVI compared to nZVI, ${ }^{40}$ which would further increase the selectivity of hydrophobic organohalides over more hydrophilic contaminants, and increase electron efficiency for target contaminants. However, the lower reactivity with nitrate could also be due to a greater abundance of FeS reactive sites relative to $\mathrm{Fe}(0) / \mathrm{Fe}$-oxide sites, the latter being more reactive with nitrate than the former.

The apparent decoupling of $\mathrm{Fe}(0)$ corrosion by water and dechlorination for S-ZVI indicate that the dechlorination by S-
ZVI does not depend on the corrosion of $\mathrm{Fe}(0)$ by water. ${ }^{19,39,68}$ The current consensus is that the $\mathrm{FeS}_{x}$ layer formed on the ZVI surface inhibits the corrosion of ZVI in water by blocking access to $\mathrm{Fe}(0)$, thus preserving the electron donating capacity for reductive dechlorination. Dechlorination mediated by direct electron transfer does not require excess TCE to maintain high $\varepsilon_{\mathrm{e}}$ as with conventional or bimetallically modified nZVI because there is no need to outcompete water for reaction sites and electrons. This difference has important practical implications. Excess TCE concentration can be easily created in the laboratory, but is difficult to maintain in the field because the aqueous TCE concentration is often limited by slow mass transfer processes (e.g., dissolution, diffusion, or desorption), even in the source area. ${ }^{70}$ For conventional ZVI, corrosion by water still occurs in the absence of high concentration of TCE, resulting in a low $\varepsilon_{\mathrm{e}}$. In contrast, the enhancement of $\varepsilon_{\mathrm{e}}$ by sulfidation is due to inhibited corrosion, which is independent of aqueous TCE concentration. Therefore, high $\varepsilon_{\mathrm{e}}$ is more likely to be realized and sustained in the field for S-ZVI.

4.1.4. Effect of forming composites with carbonaceous materials. Many carbonaceous materials have been used as supports for nZVI to form Fe-carbon composites, ${ }^{71-73}$ including activated carbon (AC), hydrochar, carbon aerogel, mesoporous carbon, graphene, and biochar. The nZVI particles are dispersed within the carbon pore matrix to prevent aggregation and to enhance mobility in the subsurface when the size of the carbon particle falls into the colloidal range (e.g., 1-2 $\mu \mathrm{m}$ CarboIron ${ }^{74}{ }^{74}$ ). A field test at a PCE-contaminated site showed that the CMC-stabilized Carbo-Iron $®$ maintained its reactivity with PCE for up to 190 days. $^{75}$ In contrast, the reactive lifetime of CMCnZVI in the subsurface was reported to be less than 7 days in a few field trials. ${ }^{49,76}$ However, it is difficult to isolate the reactivity of nZVI from biodegradation stimulated by the lower redox conditions upon nZVI injection. ${ }^{77}$ Similarly, granular AC$\mathrm{nZVI} / \mathrm{Pd}$ was reported to have $60 \% \mathrm{Fe}(0)$ remaining, while the 
unsupported nZVI counterpart was fully oxidized after one year of aging in unbuffered water under anoxic conditions. ${ }^{78}$ These findings collectively suggest that the AC helps to inhibit the reaction of ZVI with water, thereby increasing the electron efficiency of the material for dechlorination. While the mechanism is unknown, one possible explanation for the lower corrosion rate in water is that the $\mathrm{pH}$ of the water in the pores of the carbon support increases to 9 or higher due to $\mathrm{Fe}(0)$ corrosion, and remains high due to low exchange of porewater in the carbon support with the surrounding bulk water. It was previously shown that the corrosion rate of nZVI in water decreased 27-fold as the $\mathrm{pH}$ increased from 6.5 to $8.9 .^{79}$ Another possible explanation is that the PCE is concentrated on the AC support, leading to a significantly higher PCE to ZVI ratio and therefore greater selectivity and electron efficiency. It was previously shown that the reaction of TCE was increasingly favored over the reaction of water as the initial TCE concentration increased relative to the nZVI concentration, simply due to TCE outcompeting water for reduction reaction sites and/or for adsorbed $\mathrm{H}^{\mathbf{8 0}}$

In a recent laboratory study, the $\varepsilon_{\mathrm{e}}$ of PCE dechlorination by Carbo-Iron ${ }^{\circledR}$ was determined using eqn (16). ${ }^{21}$ The $\varepsilon_{e}$ value increased from 27 to $60 \%$ with decreasing particle concentration from 5 to $1.25 \mathrm{~g} \mathrm{~L}^{-1}$ at $\mathrm{pH} 8.5$ and PCE concentration of $33 \mathrm{mg} \mathrm{L}{ }^{-1}$. The change in selectivity for PCE degradation over the reduction of water to form $\mathrm{H}_{2}$ is likely the result of a 4-fold change in the relative concentration of PCE to nZVI. In comparison, the $\varepsilon_{\mathrm{e}}$ of TCE dechlorination by a variety of ZVI (nanoscale or microscale) under a range of experimental conditions (iron excess or TCE excess, $\mathrm{pH}$ : 6-10) was reported to be less than $8 \% .^{29,39,57}$ Although the contaminant type (PCE $v s$. TCE) may cause some difference in $\varepsilon_{\mathrm{e}}$ due to differences in sorption affinity for the ZVI surfaces, the significantly higher $\varepsilon_{\mathrm{e}}$ of Carbo-Iron ${ }^{\circledR}$ still suggests that the AC support can enhance the utilization efficiency of electrons for dechlorination.

\subsection{Effects of geochemistry on electron efficiency}

4.2.1. Solution pH. Solution $\mathrm{pH}$ is known to be one of the most important factors affecting ZVI reactivity ${ }^{\mathbf{8 1}}$ and its effect on ZVI particles for reductive dechlorination has been well documented. It is generally accepted that decreasing $\mathrm{pH}$ increases reductive dechlorination rate constants because of accelerated iron corrosion and depassivation of the ZVI surface at lower $\mathrm{pH}$, while an elevated $\mathrm{pH}$ value is observed to lower the ZVI reactivity due to mineral precipitation and inhibited mass transfer. ${ }^{79}$ Meanwhile, solution $\mathrm{pH}$ also affects $\mathrm{H}_{2}$ evolution. ${ }^{79}$ Therefore, it is expected that solution $\mathrm{pH}$ will affect the $\varepsilon_{\mathrm{e}}$ of ZVI particles toward target contaminants, depending on the relative extent of its effect on reductive dechlorination and $\mathrm{H}_{2}$ evolution.

$\mathrm{H}_{2}$ evolution was observed to be more sensitive to changes in $\mathrm{pH}$ than TCE dechlorination. Increasing solution $\mathrm{pH}$ from 6.5 to 8.9 decreased the HER rate of nZVI by 27 -fold while decreasing the TCE dechlorination rate by only 2 -fold. ${ }^{79}$ Similarly, Kim et al. $(2017)^{82}$ reported that the reaction of PCE with nZVI increased slightly as the $\mathrm{pH}$ was increased from 7 to 11, whereas the HER rate decreased by a factor of 3 over the same $\mathrm{pH}$ range. This suggests that the combined effect on $\varepsilon_{\mathrm{e}}$ will increase it as $\mathrm{pH}$ increases. The effect of $\mathrm{pH}$ on the $\varepsilon_{\mathrm{e}}$ of TCE dechlorination by ZVI and sulfidated ZVI has been quantified recently. When the solution $\mathrm{pH}$ increased from 6 to 9 , the $\varepsilon_{\mathrm{e}}$ of ball milled mZVI increased from $\sim 1 \%$ to $5 \%$, while that by ball milled, sulfidated mZVI increased from $\sim 3 \%$ to $20 \%{ }^{38}$ The results further demonstrate that increased $\mathrm{pH}$ inhibits the rate of the HER more than that of TCE dechlorination. This effect still has to be verified for more classes of organohalide COCs.

4.2.2. Co-existing ions. Some co-existing ions typically present in groundwater water, such as $\mathrm{SO}_{4}{ }^{2-}, \mathrm{PO}_{4}{ }^{3-}, \mathrm{Mg}^{2+}, \mathrm{Ca}^{2+}$, etc., could react with-or be adsorbed onto-iron oxides, thereby altering the composition of ZVI surface oxides, which could change the electron transfer rate from ZVI to the COC and the interaction of the COC with ZVI at the water-particle interface. Meanwhile, co-existing ions may also influence electron transfer from the $\mathrm{Fe}^{0}$ core to non-target oxidants (e.g., oxygen, $\mathrm{H}^{+}$, and water) and ultimately influence the $\varepsilon_{\mathrm{e}}$ of ZVI particles.

Groundwater anions such $\mathrm{Cl}^{-}, \mathrm{HCO}_{3}{ }^{-}$, and $\mathrm{SO}_{4}{ }^{2-}$ all inhibited TCE dechlorination by nZVI, but did not affect the HER rate of nZVI. ${ }^{80}$ Therefore, lower $\varepsilon_{\mathrm{e}}$ values are expected with the presence of these anions although $\varepsilon_{\mathrm{e}}$ measurements were not done. In a recent study, the effect of inorganic constituents (hardness $\left(\mathrm{Ca}^{2+}\right)$ and alkalinity $\left(\mathrm{HCO}_{3}{ }^{-}\right)$) on the $\varepsilon_{\mathrm{e}}$ of TCE dechlorination by mZVI was measured. ${ }^{28}$ The presence of $\mathrm{Ca}^{2+}$ $\mathrm{HCO}_{3}{ }^{-}$increased the $\varepsilon_{\mathrm{e}}$ values because it inhibited the HER more than dechlorination. In contrast, groundwater salinity (500 $\mathrm{mM} \mathrm{NaCl}, 50 \mathrm{mM} \mathrm{MgSO}_{4}, 10 \mathrm{mM} \mathrm{CaCl} 2$, and $2 \mathrm{mM}$ $\mathrm{NaHCO}_{3}$ ) decreased the $\varepsilon_{\mathrm{e}}$ of TCE dechlorination by mZVI from $50-60 \%$ to $25-40 \%$ in column tests. ${ }^{83}$ Although there are more studies on how co-existing ions affect the HER, ${ }^{\mathbf{8 4 , 8 5}}$ systematic investigation of their effect on $\varepsilon_{\mathrm{e}}$ remains to be explored.

\subsection{Effect of co-contaminants on electron efficiency}

The presence of co-contaminants (e.g., nitrate ${ }^{20}$ and chromate ${ }^{37}$ ) can cause intra-contaminant competition for the reductive capacity or reactive sites of $\mathrm{ZVI}^{\mathbf{2 0 , 3 7}}$ This competition can influence the efficiency and/or the selectivity of target contaminant reduction by ZVI. In some cases, this competition involves deposition of the co-contaminant on the ZVI surface (e.g., $\mathrm{Cr}(\mathrm{OH})_{3}$ from reductive precipitation of chromate), and the change in surface properties can increase or decrease the removal efficiency of primary contaminants. For example, it was observed that the $\varepsilon_{\mathrm{e}}$ of ball-milled S-mZVI for TCE dechlorination decreased from $\sim 30 \%$ to 0 when the $\operatorname{Cr}(\mathrm{vI})$ concentration was increased from 0 to $50 \mathrm{mg} \mathrm{L}{ }^{-1} \cdot{ }^{37}$ This is consistent with the fact that chromate is not only a competitor for electrons from $\mathrm{Fe}^{0}$, but also a strong passivator of ZVI with respect to aqueous corrosion reactions.

In other cases, the co-contaminant is not expected to contribute to new phases on the ZVI surface, but can still influence the reactivity of COCs with ZVI in other ways. The most prominent example of this involves nitrate, which is easily reduced by ZVI to $\mathrm{NH}_{4}{ }^{+}$. Although $\mathrm{NH}_{4}{ }^{+}$does not accumulate on the ZVI surface, nitrate is a well-known inhibitor for COC 
reduction by ZVI, presumably mainly because the 6-electron reduction of nitrate to $\mathrm{NH}_{4}{ }^{+}$results in oxidation and therefore passivation of ZVI. Recently, the efficiency implications of competition between COCs and nitrate has been characterized using NDMA as the primary contaminant. ${ }^{20}$ It was observed that both the rate and $\varepsilon_{\mathrm{e}}$ of NDMA reduction by unsulfidated $\mathrm{mZVI}$ were significantly inhibited by nitrate. Using sulfidated mZVI, the rate of nitrate reduction was greatly decreased, which resulted in improved $\varepsilon_{\mathrm{e}}$ for NDMA, presumably because sulfidation suppressed $\mathrm{NO}_{3}{ }^{-}$reduction and alleviated its passivating effect through the replacement of $\mathrm{Fe}^{0} / \mathrm{Fe}_{x} \mathrm{O}_{y}$ surface sites with FeS. ${ }^{20}$

\subsection{Temporal effects on electron efficiency}

Changes in contaminant concentration and reactant (i.e., ZVI) properties occur over time and space (i.e., along a flow path in porous media) throughout the reaction (treatment) processes, and these changes may affect electron efficiencies. As discussed above, many laboratory studies have used high TCE concentrations (e.g., $>200 \mathrm{mg} \mathrm{L}^{-1}$ ) relative to the ZVI dose in order to simulate source treatment with nZVI. These conditions generally produce higher $\varepsilon_{\mathrm{e}}$ for dechlorination than lower TCE concentrations (depending on the ZVI type), ${ }^{29,30,33,39}$ but as the TCE is degraded (e.g., to $<10 \mathrm{mg} \mathrm{L}^{-1}$ ) a notable decrease in $\varepsilon_{\mathrm{e}}$ is also observed. This trend is expected because lower contaminant concentrations make it less competitive with water (or other species that contribute to NRD) for reactive sites on ZVI. A similar trend has recently been reported for $\mathrm{mZVI}$, where TCE dechlorination in batch experiments using ball-milled, sulfidated mZVI gave a value of $\varepsilon_{\mathrm{e}}$ under high TCE, iron-limited conditions $(0.2 \mathrm{~g}$ $\mathrm{L}^{-1} \mathrm{Fe}$ and $250 \mathrm{mg} \mathrm{L}^{-1} \mathrm{TCE}$ ), which was 10 -fold greater than that under low TCE, excess iron conditions $\left(10 \mathrm{~g} \mathrm{~L}^{-1} \mathrm{Fe}\right.$ and $10 \mathrm{mg} \mathrm{L}{ }^{-1}$ TCE). ${ }^{29}$ However, sulfidation in general shows less effect of COC concentration on $\varepsilon_{\mathrm{e}}$ compared to regular ZVI because it inhibits the competing reaction with water.

On the reactant side, the reactivity of ZVI generally decreases over time due to aging processes that include passivation by the iron minerals that precipitate from $\mathrm{Fe}(\mathrm{II})$ and $\mathrm{Fe}(\mathrm{III})$ that are formed from corrosion of $\mathrm{Fe}(0){ }^{36}$ The effects of aging on the reactivity of nZVI with respect to dechlorination and the HER have been characterized in two earlier studies using nZVI. ${ }^{\mathbf{9 9 , 8 6}}$ Using TCE as the target contaminant, the dechlorination rate rapidly decreased over 10 days and then remained stable or increased slightly over the following $\sim 200$ days, whereas the HER rate was relatively stable throughout the entire experiment. ${ }^{79}$ Using carbon tetrachloride as the target contaminant, dechlorination rates increased in the first few days and then declined and leveled out over $\sim 35$ days, while the $\mathrm{H}_{2}$ production rate followed the inverse trend. The former study ${ }^{79}$ did not address efficiency directly, but the results suggest that the electron efficiency and selectivity of nZVI decrease initially and then remain relatively stable. The latter study ${ }^{86}$ also did not calculate efficiencies, but it included a quantitative correlation analysis between dechlorination and HER rates, which showed a hysteresis loop that suggests that the efficiency/selectivity of the reaction does change with aging time. However, the difference between these results may only be due to the time scale of aging, since the greatest effects occurred near the beginning of the sampled time periods. For S-nZVI, the effects of aging on $\varepsilon_{\mathrm{e}}$ are shown to be much less significant than those on conventional nZVI, ${ }^{40}$ although the effects of aging depend on the sulfidation method used and on the conditions of the aging process (i.e. with COCs present or absent). This could also be attributed to the inhibited reaction with water, which limits aging and transformation of the particle.

The practical implications of the effects of temporal changes on $\varepsilon_{\mathrm{e}}$ for dechlorination in a source zone are described in Fig. 5. For conventional ZVI, $\varepsilon_{\mathrm{e}}$ for dechlorination could quickly decrease with decreasing contaminant concentration after ZVI emplacement. In contrast, the selectivity for the reduction of NRD, especially water, increases, which diminishes the total $\mathrm{Fe}(0)$ content over time, thus resulting in the rebound of aqueous TCE concentration (Fig. 5A). For S-ZVI, inhibited reduction of water not only maintains high selectivity for TCE regardless of TCE concentration, but also preserves the total $\mathrm{Fe}(0)$ content over aging, increasing its long-term effectiveness (Fig. 5B).
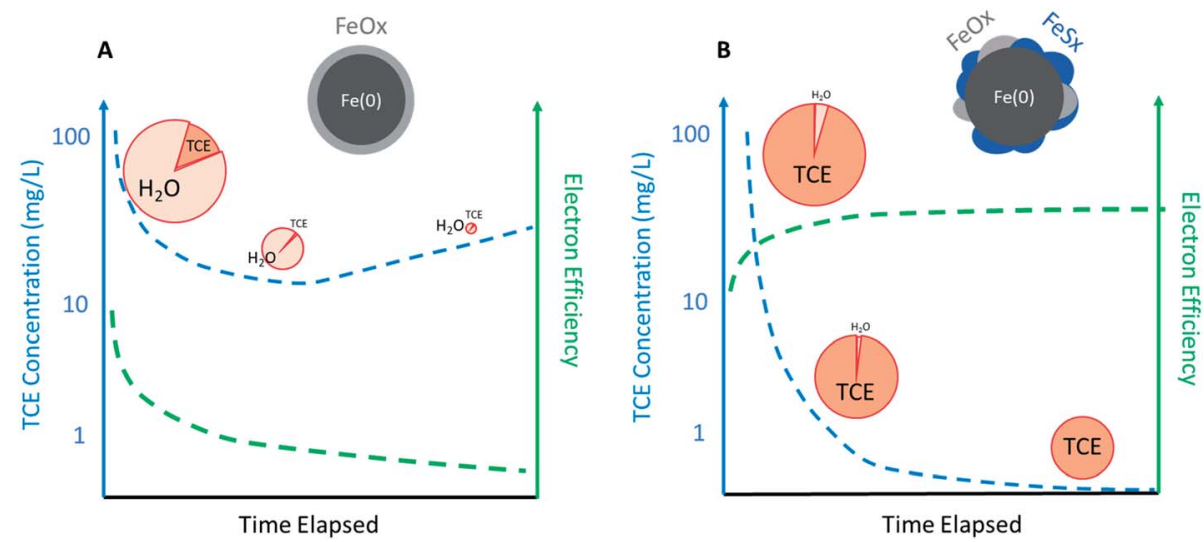

Fig. 5 Likely temporal changes of TCE concentration (left axis) and electron efficiency (right axis) during a scenario of source remediation by (A) regular ZVI and (B) sulfidated ZVI (the size of the pie represents the total capacity of $\mathrm{Fe}(\mathrm{O})$ and the slices represent selectivity toward TCE or $\mathrm{H}_{2} \mathrm{O}$. Efficiency curve shown in B is based on the data of sulfidated CMC-nZVI reported in Fan et al. ${ }^{68}$ and Xu et al. ${ }^{57}$ ). 


\section{Implications for other systems}

The majority of this review focused on TCE dechlorination by ZVI because that system is so widely studied that a considerable quantity of research on efficiency and selectivity aspects is now available. In many respects, it is a good model system for developing general concepts regarding efficiency and selectivity that should apply to other systems. For example, the strength of ZVI as a reductant means that several "input" reactions will be in competition (with TCE, $\mathrm{H}_{2} \mathrm{O}$, nitrate, etc.) and these reactions lead to several competing "output" reactions (formation of dechlorination products, iron oxides, etc.). Taken together in various combinations, the system exhibits a variety of efficiencies and selectivities that should be applicable to other environmental processes.

The efficiency and selectivity concepts developed in this review for TCE certainly will be applicable to other contaminants that are degraded by ZVI. For other chlorinated solvents (carbon tetrachloride, 1,1,1-trichloroethane, 1,2,3-trichloropropane, etc.) the only limitation is the lack of data, but this may be alleviated by studies forthcoming in the near future. For other organic contaminants (energetics like 2,4,6-trinitrotoluene and nitro-group containing pesticides like parathion, azo dyes, etc. $),{ }^{87,88}$ all of the concepts and definitions developed here will be applicable, although the specifics of their application may vary. For example, nitro reduction by ZVI generally is faster compared with dechlorination, and consumes 6 electrons to form fully reduced amino products, so it might outcompete other reduction processes resulting in higher electron efficiencies. Similar generalizations should apply to the removal of metals, metalloids, and other inorganic contaminants (e.g., chlorine residual) and some of them were addressed above as competitors with TCE for reaction with ZVI.

Another possible extension of the efficiency and selectivity concepts developed here is to related treatment or remediation processes that do not involve ZVI. A compelling example of this is contaminant reduction with metals that are even more strongly reducing than ZVI, namely, zero-valent zinc (ZVZ) $)^{89-92}$ and zero-valent magnesium $(\mathrm{ZVMg}){ }^{93-95}$ The reduction of water by ZVZ and ZVMg is much more favorable than ZVI, so the HER is likely to compete more strongly with contaminants for electrons from the metal, making efficiency and selectivity even greater issues for practical applications of these reductants. In some respects, ZVZ (and probably also ZVMg) is an even better example of how operational factors influence efficiency and selectivity because the passivation of these metals can be much more complete than with ZVI, so the rates of contaminant and water reduction and the associated electron efficiencies are likely to vary greatly with conditions that affect the passivation of these metals. This, in turn, could result in treatment processes that are effective, or ineffective, in ways that are not yet known.

Beyond engineered water treatment systems, there should even be applications of efficiency/selectivity concepts to natural biogeochemical redox processes that contribute to the fate of contaminants. Finally, the effect of these processes has been termed abiotic natural attenuation (ANA), and there is considerable recent and on-going research to delineate the scope and core concepts of ANA. ${ }^{96-98}$ The literature on ANA is not mature enough to include detailed, quantitative studies of efficiency and selectivity, but the concepts certainly are applicable. For example, if TCE dechlorination in an anoxic aquifer includes abiotic reduction by iron oxides and sulfides and these phases are present in finite quantities, then the efficiency with which these phases provide electrons for dechlorination will determine if there is capacity in the system to achieve treatment goals. In one respect, iron oxide/sulfide systems are much simpler than ZVI systems because the former generally does not reduce water, so there is no significant HER no matter what other side reactions involved. On the other hand, the iron oxide/ sulfide systems are more complex because they can be formed by in situ biogeochemical processes, whereas the ZVI system is limited by the quantity of the reagent provided.

\section{Conflicts of interest}

There are no conflicts to declare.

\section{Acknowledgements}

This material is based on work supported by the National Natural Science Foundation of China (51308312 and 51908500), the U. S. National Science Foundation, EF-1266252, the Center for the Environmental Implications of NanoTechnology (CEINT), and the Strategic Environmental Research and Development Program of the U. S. Department of Defense, Award Numbers ER-2308, ER-2620, and ER-2621. This report has not been subject to review by any sponsor and therefore does not necessarily reflect agency views and no official endorsements should be inferred.

\section{References}

1 D. Fan, Y. Lan, P. G. Tratnyek, R. L. Johnson, J. Filip, D. M. O'Carroll, A. Nunez Garcia and A. Agrawal, Sulfidation of iron-based materials: a review of processes and implications for water treatment and remediation, Environ. Sci. Technol., 2017, 51, 13070-13085, DOI: 10.1021/ acs.est.7b04177.

2 T. Phenrat, G. V. Lowry and P. Babakhani, Nanoscale zerovalent iron (NZVI) for environmental decontamination: a brief history of 20 years of research and field-scale application, in Nanoscale Zerovalent Iron Particles for Environmental Restoration: From Fundamental Science to Field Scale Engineering Applications, ed. T. Phenrat and G. V. Lowry, Springer International Publishing, Cham, 2019, pp. 1-43.

3 D. O'Carroll, B. Sleep, M. Krol, H. Boparai and C. Kocur, Nanoscale zero valent iron and bimetallic particles for contaminated site remediation, Adv. Water Resour., 2013, 51, 104-122, DOI: 10.1016/j.advwatres.2012.02.005.

4 W. L. Yan, H. L. Lien, B. E. Koel and W. X. Zhang, Iron nanoparticles for environmental clean-up: recent 
developments and future outlook, Environ. Sci.: Processes Impacts, 2013, 15, 63-77, DOI: 10.1039/c2em30691c.

5 X. H. Guan, Y. K. Sun, H. J. Qin, J. X. Li, I. M. C. Lo, D. He and H. R. Dong, The limitations of applying zero-valent iron technology in contaminants sequestration and the corresponding countermeasures: the development in zerovalent iron technology in the last two decades (1994-2014), Water Res., 2015, 75, 224-248, DOI: 10.1016/ j.watres.2015.02.034.

6 T. L. Johnson, M. M. Scherer and P. G. Tratnyek, Kinetics of halogenated organic compound degradation by iron metal, Environ. Sci. Technol., 1996, 30, 2634-2640, DOI: 10.1021/ Es9600901.

7 W. A. Arnold and A. L. Roberts, Pathways and kinetics of chlorinated ethylene and chlorinated acetylene reaction with Fe(0) particles, Environ. Sci. Technol., 2000, 34, 17941805, DOI: 10.1021/Es990884q.

8 Y. K. Sun, J. X. Li, T. L. Huang and X. H. Guan, The influences of iron characteristics, operating conditions and solution chemistry on contaminants removal by zero-valent iron: a review, Water Res., 2016, 100, 277-295, DOI: 10.1016/ j.watres.2016.05.031.

9 J. Filip, J. Kolarik, E. Petala, M. Petr, O. Sracek and R. Zboril, Nanoscale zerovalent iron particles for treatment of metalloids, in Nanoscale Zerovalent Iron for Environmental Restoration: From Fundamental Science to Field Scale Engineering Applications, ed. T. Phenrat and G. V. Lowry, Springer International Publishing AG, Cham, 2019, pp. 157-199.

10 X. Q. Li and W. X. Zhang, Sequestration of metal cations with zerovalent iron nanoparticles-a study with high resolution X-ray photoelectron spectroscopy (HR-XPS), J. Phys. Chem. C, 2007, 111, 6939-6946, DOI: 10.1021/jp0702189.

11 Y. D. Zou, X. X. Wang, A. Khan, P. Y. Wang, Y. H. Liu, A. Alsaedi, T. Hayat and X. K. Wang, Environmental remediation and application of nanoscale zero-valent iron and its composites for the removal of heavy metal ions: a review, Environ. Sci. Technol., 2016, 50, 7290-7304, DOI: 10.1021/acs.est.6b01897.

12 Y. Su, A. S. Adeleye, A. A. Keller, Y. Huang, C. Dai, X. Zhou and Y. Zhang, Magnetic sulfide-modified nanoscale zerovalent iron (S-nZVI) for dissolved metal ion removal, Water Res., 2015, 74, 47-57, DOI: 10.1016/ j.watres.2015.02.004.

13 J. L. Qiao, Y. D. Song, Y. K. Sun and X. H. Guan, Effect of solution chemistry on the reactivity and electron selectivity of zerovalent iron toward Se(VI) removal, Chem. Eng. J., 2018, 353, 246-253, DOI: 10.1016/j.cej.2018.07.113.

14 J. Li, X. Zhang, M. Liu, B. Pan, W. Zhang, Z. Shi and X. Guan, Enhanced reactivity and electron selectivity of sulfidated zerovalent iron toward chromate under aerobic conditions, Environ. Sci. Technol., 2018, 52, 2988-2997, DOI: 10.1021/ acs.est.7b06502.

15 H. Qin, J. Li, H. Yang, B. Pan, W. Zhang and X. Guan, Coupled effect of ferrous ion and oxygen on the electron selectivity of zerovalent iron for selenate sequestration, Environ. Sci. Technol., 2017, 51, 5090-5097, DOI: 10.1021/acs.est.6b04832.
16 J. F. Ling, J. L. Qiao, Y. D. Song and Y. K. Sun, Influence of coexisting ions on the electron efficiency of sulfidated zerovalent iron toward Se(VI) removal, Chem. Eng. J., 2019, 378, 122124, DOI: 10.1016/j.cej.2019.122124.

17 P. Fan, L. N. Li, Y. K. Sun, J. L. Qiao, C. H. Xu and X. H. Guan, Selenate removal by $\mathrm{Fe}-0$ coupled with ferrous iron, hydrogen peroxide, sulfidation, and weak magnetic field: a comparative study, Water Res., 2019, 159, 375-384, DOI: 10.1016/j.watres.2019.05.037.

18 M. Li, Y. Mu, H. Shang, C. Mao, S. Cao, Z. Ai and L. Zhang, Phosphate modification enables high efficiency and electron selectivity of nZVI toward Cr(VI) removal, Appl. Catal., B, 2019, 263, 118364-118370, DOI: 10.1016/ j.apcatb.2019.118364.

19 S. Bhattacharjee and S. Ghoshal, Optimal design of sulfidated nanoscale zerovalent iron for enhanced trichloroethene degradation, Environ. Sci. Technol., 2018, 52, 11078-11086, DOI: 10.1021/acs.est.8b02399.

20 H. Qin, X. Guan and P. G. Tratnyek, Effects of sulfidation and nitrate on the reduction of N-nitrosodimethylamine by zerovalent iron, Environ. Sci. Technol., 2019, 53, 9744-9754, DOI: 10.1021/acs.est.9b02419.

21 M. Vogel, A. Georgi, F. D. Kopinke and K. Mackenzie, Sulfidation of ZVI/AC composite leads to highly corrosionresistant nanoremediation particles with extended lifetime, Sci. Total Environ., 2019, 665, 235-245, DOI: 10.1016/ j.scitotenv.2019.02.136.

22 A. D. McNaught and A. Wilkinson, The IUPAC Compendium of Chemical Terminology (The "Gold Book”), Blackwell Scientific Publications, Oxford, 2nd edn, 1997.

23 S.-H. Xie, G.-Q. Peng, X.-M. Tu, H.-X. Qian and X.-R. Zeng, Febased powders prepared by ball-milling with considerable degradation efficiency to methyl orange compared with Febased metallic glasses, Acta Metall. Sin., 2018, 31, 12071214, DOI: 10.1007/s40195-018-0751-3.

24 M. Támara and E. C. Butler, Effects of iron purity and groundwater characteristics on rates and products in the degradation of carbon tetrachloride by iron metal, Environ. Sci. Technol., 2004, 38, 1866-1876, DOI: 10.1021/es0305508.

25 J. T. Nurmi, P. G. Tratnyek, V. Sarathy, D. R. Baer, J. E. Amonette, K. Pecher, C. Wang, J. C. Linehan, D. W. Matson, R. L. Penn and M. D. Driessen, Characterization and properties of metallic iron nanoparticles: spectroscopy, electrochemistry, and kinetics, Environ. Sci. Technol., 2005, 39, 1221-1230, DOI: 10.1021/ es049190u.

26 V. Sarathy, P. G. Tratnyek, J. T. Nurmi, D. R. Baer, J. E. Amonette, C. Chun, R. L. Penn and E. J. Reardon, Aging of iron nanoparticles in aqueous solution: effects on structure and reactivity, J. Phys. Chem. C, 2008, 112, 22862293, DOI: 10.1021/jp0777418.

27 Y. Han and W. Yan, Reductive dechlorination of trichloroethene by zero-valent iron nanoparticles: reactivity enhancement through sulfidation treatment, Environ. Sci. Technol., 2016, 50, 12992-13001, DOI: 10.1021/ acs.est.6b03997.

28 F. L. Tang, J. Xin, T. Y. Zheng, X. L. Zheng, X. P. Yang and O. Kolditz, Individual and combined effects of humic acid, 
bicarbonate and calcium on TCE removal kinetics, aging behavior and electron efficiency of mZVI particles, Chem. Eng. J., 2017, 324, 324-335, DOI: 10.1016/j.cej.2017.04.144.

29 Y. Gu, B. Wang, F. He, M. J. Bradley and P. G. Tratnyek, Mechanochemically sulfidated microscale zero valent iron: pathways, kinetics, mechanism, and efficiency of trichloroethylene dechlorination, Environ. Sci. Technol., 2017, 51, 12653-12662, DOI: 10.1021/acs.est.7b03604.

30 Y. Q. Liu, S. A. Majetich, R. D. Tilton, D. S. Sholl and G. V. Lowry, TCE dechlorination rates, pathways, and efficiency of nanoscale iron particles with different properties, Environ. Sci. Technol., 2005, 39, 1338-1345, DOI: 10.1021/es049195r.

31 Y. Q. Liu, H. Choi, D. Dionysiou and G. V. Lowry, Trichloroethene hydrodechlorination in water by highly disordered monometallic nanoiron, Chem. Mater., 2005, 17, 5315-5322, DOI: $10.1021 / \mathrm{cm} 0511217$.

32 D. Fan, D. M. O'Carroll, D. W. Elliott, Z. Xiong, P. G. Tratnyek, R. L. Johnson and A. N. Garcia, Selectivity of nano zerovalent iron in in situ chemical reduction: challenges and improvements, Remed. J., 2016, 26, 27-40, DOI: $10.1002 / \mathrm{rem} .21481$.

33 J. Xu, Z. Cao, H. Zhou, Z. Lou, Y. Wang, X. Xu and G. V. Lowry, Sulfur dose and sulfidation time affect reactivity and selectivity of post-sulfidized nanoscale zerovalent iron, Environ. Sci. Technol., 2019, 53, 1334413352, DOI: 10.1021/acs.est.9b04210.

34 H. Liu, Q. Wang, C. Wang and X. Z. Li, Electron efficiency of zero-valent iron for groundwater remediation and wastewater treatment, Chem. Eng. J., 2013, 215, 90-95, DOI: 10.1016/j.cej.2012.11.010.

35 P. Schöftner, G. Waldner, W. Lottermoser, M. Stöger-Pollach, P. Freitag and T. G. Reichenauer, Electron efficiency of nZVI does not change with variation of environmental parameters, Sci. Total Environ., 2015, 535, 69-78, DOI: 10.1016/j.scitotenv.2015.05.033.

36 B. C. Reinsch, B. Forsberg, R. L. Penn, C. S. Kim and G. V. Lowry, Chemical transformations during aging of zerovalent iron nanoparticles in the presence of common groundwater dissolved constituents, Environ. Sci. Technol., 2010, 44, 3455-3461, DOI: 10.1021/es902924h.

37 H. Zou, E. Hu, S. Yang, L. Gong and F. He, Chromium(VI) removal by mechanochemically sulfidated zero valent iron and its effect on dechlorination of trichloroethene as a cocontaminant, Sci. Total Environ., 2019, 650, 419-426, DOI: 10.1016/j.scitotenv.2018.09.003.

38 Y. Gu, L. Gong, J. Qi, S. Cai, W. Tu and F. He, Sulfidation mitigates the passivation of zero valent iron at alkaline pHs: experimental evidences and mechanism, Water Res., 2019, 159, 233-241, DOI: 10.1016/j.watres.2019.04.061.

39 F. He, Z. Li, S. Shi, W. Xu, H. Sheng, Y. Gu, Y. Jiang and B. Xi, Dechlorination of excess trichloroethene by bimetallic and sulfidated nanoscale zero-valent iron, Environ. Sci. Technol., 2018, 52, 8627-8637, DOI: 10.1021/acs.est.8b01735.

40 J. Xu, Y. Wang, C. Weng, W. Bai, Y. Jiao, R. Kaegi and G. V. Lowry, Reactivity, selectivity, and long-term performance of sulfidized nanoscale zerovalent iron with different properties, Environ. Sci. Technol., 2019, 53, 59365945, DOI: 10.1021/acs.est.9b00511.

41 D. M. Cwiertny, S. J. Bransfield and A. L. Roberts, Influence of the oxidizing species on the reactivity of iron-based bimetallic reductants, Environ. Sci. Technol., 2007, 41, 3734-3740, DOI: 10.1021/es062993s.

42 E. J. Kim, J. H. Kim, Y. S. Chang, D. Turcio-Ortega and P. G. Tratnyek, Effects of metal ions on the reactivity and corrosion electrochemistry of $\mathrm{Fe} / \mathrm{FeS}$ nanoparticles, Environ. Sci. Technol., 2014, 48, 4002-4011, DOI: 10.1021/ es405622d.

43 Y. L. Han and W. L. Yan, Bimetallic nickel-iron nanoparticles for groundwater decontamination: effect of groundwater constituents on surface deactivation, Water Res., 2014, 66, 149-159, DOI: 10.1016/j.watres.2014.08.001.

44 C. Grittini, M. Malcomson, Q. Fernando and N. Korte, Rapid dechlorination of polychlorinated-biphenyls on the surface of a Pd/Fe bimetallic system, Environ. Sci. Technol., 1995, 29, 2898-2900, DOI: 10.1021/es00011a029.

45 N. E. Korte, J. L. Zutman, R. M. Schlosser, L. Liang, B. Gu and Q. Fernando, Field application of palladized iron for the dechlorination of trichloroethene, Waste Manag., 2000, 20, 687-694, DOI: 10.1016/S0956-053x(00)00037-4.

$46 \mathrm{~T}$. Li and J. Farrell, Reductive dechlorination of trichloroethene and carbon tetrachloride using iron and palladized-iron cathodes, Environ. Sci. Technol., 2000, 34, 173-179, DOI: 10.1021/Es9907358.

47 B. Schrick, J. L. Blough, A. D. Jones and T. E. Mallouk, Hydrodechlorination of trichloroethylene to hydrocarbons using bimetallic nickel-iron nanoparticles, Chem. Mater., 2002, 14, 5140-5147, DOI: 10.1021/cm020737i.

$48 \mathrm{~F}$. He and D. Y. Zhao, Hydrodechlorination of trichloroethene using stabilized Fe-Pd nanoparticles: reaction mechanism and effects of stabilizers, catalysts and reaction conditions, Appl. Catal., B, 2008, 84, 533-540, DOI: 10.1016/j.apcatb.2008.05.008.

49 F. He, D. Y. Zhao and C. Paul, Field assessment of carboxymethyl cellulose stabilized iron nanoparticles for in situ destruction of chlorinated solvents in source zones, Water Res., 2010, 44, 2360-2370, DOI: 10.1016/ j.watres.2009.12.041.

50 A. Gavaskar, L. Tatar and W. Condit, Cost and performance report nanoscale zerovalent iron technologies for source remediation, NAVFAC, No. CR-05-007-ENV, 2005.

51 W. L. Yan, A. A. Herzing, X. Q. Li, C. J. Kiely and W. X. Zhang, Structural evolution of Pd-doped nanoscale zero-valent iron (nZVI) in aqueous media and implications for particle aging and reactivity, Environ. Sci. Technol., 2010, 44, 4288-4294, DOI: 10.1021/es100051q.

52 F. He and D. Y. Zhao, Preparation and characterization of a new class of starch-stabilized bimetallic nanoparticles for degradation of chlorinated hydrocarbons in water, Environ. Sci. Technol., 2005, 39, 3314-3320, DOI: 10.1021/es048743y.

53 T. Phenrat, N. Saleh, K. Sirk, H. J. Kim, R. D. Tilton and G. V. Lowry, Stabilization of aqueous nanoscale zerovalent iron dispersions by anionic polyelectrolytes: adsorbed anionic polyelectrolyte layer properties and their effect on 
aggregation and sedimentation, J. Nanopart. Res., 2008, 10, 795-814, DOI: 10.1007/s11051-007-9315-6.

54 P. G. Tratnyek, A. J. Salter-Blanc, J. T. Nurmi, J. E. Amonette, J. Liu, C. M. Wang, A. Dohnalkova and D. R. Baer, Reactivity of zerovalent metals in aquatic media: effects of organic surface coatings, in Aquatic Redox Chemistry, ed. P. G. Tratnyek, T. J. Grundl and S. B. Haderlein, 2011, vol. 1071, pp. 381-406, DOI: 10.1021/bk-2011-1071.ch018.

55 N. Saleh, K. Sirk, Y. Q. Liu, T. Phenrat, B. Dufour, K. Matyjaszewski, R. D. Tilton and G. V. Lowry, Surface modifications enhance nanoiron transport and NAPL targeting in saturated porous media, Environ. Eng. Sci., 2007, 24, 45-57, DOI: 10.1089/ees.2007.24.45.

56 T. Phenrat, Y. Q. Liu, R. D. Tilton and G. V. Lowry, Adsorbed polyelectrolyte coatings decrease Fe-0 nanoparticle reactivity with TCE in water: conceptual model and mechanisms, Environ. Sci. Technol., 2009, 43, 1507-1514, DOI: 10.1021/ es802187d.

57 W. Xu, Z. Li, S. Shi, J. Qi, S. Cai, Y. Yu, D. M. O'Carroll and F. He, Carboxymethyl cellulose stabilized and sulfidated nanoscale zero-valent iron: characterization and trichloroethene dechlorination, Appl. Catal., B, 2020, 262, 118303, DOI: 10.1016/j.apcatb.2019.118303.

58 R. L. Johnson, G. O. Johnson, J. T. Nurmi and P. G. Tratnyek, Natural organic matter enhanced mobility of nano zerovalent iron, Environ. Sci. Technol., 2009, 43, 5455-5460, DOI: 10.1021/es900474f.

59 P. G. Tratnyek, M. M. Scherer, B. L. Deng and S. D. Hu, Effects of natural organic matter, anthropogenic surfactants, and model quinones on the reduction of contaminants by zero-valent iron, Water Res., 2001, 35, 4435-4443, DOI: 10.1016/S0043-1354(01)00165-8.

60 Y. T. Han, S. Ghoshal, G. V. Lowry and J. W. Chen, A comparison of the effects of natural organic matter on sulfidated and nonsulfidated nanoscale zerovalent iron colloidal stability, toxicity, and reactivity to trichloroethylene, Sci. Total Environ., 2019, 671, 254-261, DOI: 10.1016/j.scitotenv.2019.03.343.

61 J. Li, X. Zhang, Y. Sun, L. Liang, B. Pan, W. Zhang and X. Guan, Advances in sulfidation of zerovalent iron for water decontamination, Environ. Sci. Technol., 2017, 51, 13533-13544, DOI: 10.1021/acs.est.7b02695.

62 Y. Su, G. V. Lowry, D. Jassby and Y. Zhang, Sulfide-modified NZVI (S-NZVI): synthesis, characterization, and reactivity, in Nanoscale Zerovalent Iron Particles for Environmental Restoration: From Fundamental Science to Field Scale Engineering Applications, ed. T. Phenrat and G. V. Lowry, Springer International Publishing, Cham, 2019, pp. 359386.

63 M. Mangayayam, K. Dideriksen, M. Ceccato and D. J. Tobler, The structure of sulfidized zero-valent iron by one-pot synthesis: impact on contaminant selectivity and long-term performance, Environ. Sci. Technol., 2019, 53, 4389-4396, DOI: 10.1021/acs.est.8b06480.

64 S. Islam, Y. Han and W. Yan, Reactions of chlorinated ethenes with surface-sulfided iron materials: reactivity enhancement and inhibition effects, Environ. Sci.: Processes Impacts, 2020, DOI: 10.1039/C9EM00593E.

65 Z. Cao, X. Liu, J. Xu, J. Zhang, Y. Yang, J. L. Zhou, X. H. Xu and G. V. Lowry, Removal of antibiotic florfenicol by sulfide-modified nanoscale zero-valent iron, Environ. Sci. Technol., 2017, 51, 11269-11277, DOI: 10.1021/ acs.est.7b02480.

66 S. R. Rajajayavel and S. Ghoshal, Enhanced reductive dechlorination of trichloroethylene by sulfidated nanoscale zerovalent iron, Water Res., 2015, 78, 144-153, DOI: 10.1016/j.watres.2015.04.009.

67 H. J. Qin, X. H. Guan, J. Z. Bandstra, R. L. Johnson and P. G. Tratnyek, Modeling the kinetics of hydrogen formation by zerovalent iron: effects of sulfidation on micro- and nano-scale particles, Environ. Sci. Technol., 2018, 52, 13887-13896, DOI: 10.1021/acs.est.8b04436.

68 D. Fan, G. O'Brien Johnson, P. G. Tratnyek and R. L. Johnson, Sulfidation of nano zerovalent iron (nZVI) for improved selectivity during in situ chemical reduction (ISCR), Environ. Sci. Technol., 2016, 50, 9558-9565, DOI: 10.1021/acs.est.6b02170.

69 C. H. Xu, B. L. Zhang, L. J. Zhu, S. Lin, X. P. Sun, Z. Jiang and P. G. Tratnyek, Sequestration of antimonite by zerovalent iron: using weak magnetic field effects to enhance performance and characterize reaction mechanisms, Environ. Sci. Technol., 2016, 50, 1483-1491, DOI: 10.1021/ acs.est.5b05360.

70 F. Fagerlund, T. H. Illangasekare, T. Phenrat, H. J. Kim and G. V. Lowry, PCE dissolution and simultaneous dechlorination by nanoscale zero-valent iron particles in a DNAPL source zone, J. Contam. Hydrol., 2012, 131, 9-28, DOI: 10.1016/j.jconhyd.2011.08.011.

71 S. Wang, M. Zhao, M. Zhou, Y. C. Li, J. Wang, B. Gao, S. Sato, K. Feng, W. Yin, A. D. Igalavithana, P. Oleszczuk, X. Wang and Y. S. Ok, Biochar-supported nZVI (nZVI/BC) for contaminant removal from soil and water: a critical review, J. Hazard. Mater., 2019, 373, 820-834, DOI: 10.1016/ j.jhazmat.2019.03.080.

72 S. C. Wang, Y. D. Song and Y. K. Sun, Performance and mechanism of contaminants removal by carbon materialsmodified zerovalent iron, Prog. Chem., 2019, 31, 422-432, DOI: $10.7536 / \mathrm{pc} 180726$.

73 J. Gao, W. Wang, A. J. Rondinone, F. He and L. Y. Liang, Degradation of trichloroethene with a novel ball milled FeC nanocomposite, J. Hazard. Mater., 2015, 300, 443-450, DOI: 10.1016/j.jhazmat.2015.07.038.

74 S. Bleyl, F.-D. Kopinke and K. Mackenzie, Carbo-Iron ${ }^{\circledR}-$ Synthesis and stabilization of $\mathrm{Fe}(0)$-doped colloidal activated carbon for in situ groundwater treatment, Chem. Eng. J., 2012, 191, 588-595, DOI: 10.1016/j.cej.2012.03.021.

75 K. Mackenzie, S. Bleyl, F. D. Kopinke, H. Doose and J. Bruns, Carbo-Iron as improvement of the nanoiron technology: from laboratory design to the field test, Sci. Total Environ., 2016, 563, 641-648, DOI: 10.1016/j.scitotenv.2015.07.107.

76 R. L. Johnson, J. T. Nurmi, G. S. O. Johnson, D. M. Fan, R. L. O. Johnson, Z. Q. Shi, A. J. Salter-Blanc, P. G. Tratnyek and G. V. Lowry, Field-scale transport and 
transformation of carboxymethylcellulose-stabilized nano zero-valent iron, Environ. Sci. Technol., 2013, 47, 15731580, DOI: 10.1021/es304564q.

77 C. M. D. Kocur, L. Lomheim, H. K. Boparai, A. I. A. Chowdhury, K. P. Weber, L. M. Austrins, E. A. Edwards, B. E. Sleep and D. M. O'Carroll, Contributions of abiotic and biotic dechlorination following carboxymethyl cellulose stabilized nanoscale zero valent iron injection, Environ. Sci. Technol., 2015, 49, 86488656, DOI: 10.1021/acs.est.5b00719.

78 H. Choi, S. R. Al-Abed and S. Agarwal, Effects of aging and oxidation of palladized iron embedded in activated carbon on the dechlorination of 2-chlorobiphenyl, Environ. Sci. Technol., 2009, 43, 4137-4142, DOI: 10.1021/es803535b.

79 Y. Liu and G. V. Lowry, Effect of particle age ( $\mathrm{Fe}^{0}$ content) and solution $\mathrm{pH}$ on NZVI reactivity: $\mathrm{H}_{2}$ evolution and TCE dechlorination, Environ. Sci. Technol., 2006, 40, 6085-6090, DOI: $10.1021 /$ es060685o.

80 Y. Liu, T. Phenrat and G. V. Lowry, Effect of TCE concentration and dissolved groundwater solutes on NZVIpromoted TCE dechlorination and $\mathrm{H}_{2}$ evolution, Environ. Sci. Technol., 2007, 41, 7881-7887, DOI: 10.1021/es0711967.

81 S. Bae and K. Hanna, Reactivity of nanoscale zero-valent iron in unbuffered systems: effect of $\mathrm{pH}$ and $\mathrm{Fe}(\mathrm{II})$ dissolution, Environ. Sci. Technol., 2015, 49, 10536-10543, DOI: 10.1021/ acs.est.5b01298.

82 H. J. Kim, M. Leitch, B. Naknakorn, R. D. Tilton and G. V. Lowry, Effect of emplaced nZVI mass and groundwater velocity on PCE dechlorination and hydrogen evolution in water-saturated sand, J. Hazard. Mater., 2017, 322, 136-144, DOI: 10.1016/j.jhazmat.2016.04.037.

83 J. Xin, F. Tang, J. Yan, C. La, X. Zheng and W. Liu, Investigating the efficiency of microscale zero valent ironbased in situ reactive zone (mZVI-IRZ) for TCE removal in fresh and saline groundwater, Sci. Total Environ., 2018, 626, 638-649, DOI: 10.1016/j.scitotenv.2018.01.115.

84 H. Paar, A. S. Ruhl and M. Jekel, Influences of nanoscale zero valent iron loadings and bicarbonate and calcium concentrations on hydrogen evolution in anaerobic column experiments, Water Res., 2015, 68, 731-739, DOI: 10.1016/j.watres.2014.10.043.

85 J. Xin, F. L. Tang, X. L. Zheng, H. Shao, O. Kolditz and X. Lu, Distinct kinetics and mechanisms of mZVI particles aging in saline and fresh groundwater: $\mathrm{H}-2$ evolution and surface passivation, Water Res., 2016, 100, 80-87, DOI: 10.1016/ j.watres.2016.04.074.

86 V. Sarathy, P. G. Tratnyek, J. T. Nurmi, D. R. Baer, J. E. Amonette, C. L. Chun, R. L. Penn and E. J. Reardon, Aging of iron nanoparticles in aqueous solution: effects on structure and reactivity, J. Phys. Chem. C, 2008, 112, 22862293, DOI: 10.1021/jp0777418.

87 F. L. Fu, D. D. Dionysiou and H. Liu, The use of zero-valent iron for groundwater remediation and wastewater treatment: a review, J. Hazard. Mater., 2014, 267, 194-205, DOI: 10.1016/j.jhazmat.2013.12.062.
88 T. Phenrat, T. S. T. Le, B. Naknakorn and G. V. Lowry, Chemical reduction and oxidation of organic contaminants by nanoscale zerovalent iron, in Nanoscale Zerovalent Iron Particles for Environmental Restoration: From Fundamental Science to Field Scale Engineering Applications, ed. T. Phenrat and G. V. Lowry, Springer International Publishing, Cham, 2019, pp. 97-155.

89 T. Tang, G. N. Lu, R. Wang, H. Chen, Y. C. Fang, K. B. Huang, J. Y. Zheng, M. Y. Zou, X. Q. Tao, H. Yin and Z. Dang, Debromination of polybrominated diphenyl ethers (PBDEs) by zero valent zinc: mechanisms and predicting descriptors, J. Hazard. Mater., 2018, 352, 165-171, DOI: 10.1016/j.jhazmat.2018.03.038.

90 V. Bokare, J. L. Jung, Y. Y. Chang and Y. S. Chang, Reductive dechlorination of octachlorodibenzo-p-dioxin by nanosized zero-valent zinc: modeling of rate kinetics and congener profile, J. Hazard. Mater., 2013, 250, 397-402, DOI: 10.1016/ j.jhazmat.2013.02.020.

91 A. J. Salter-Blanc, E. J. Suchomel, J. H. Fortuna, J. T. Nurmi, C. Walker, T. Krug, S. O'Hara, N. Ruiz, T. Morley and P. G. Tratnyek, Evaluation of zerovalent zinc for treatment of 1,2,3-trichloropropane-contaminated groundwater: laboratory and field assessment, Ground Water Monit. R., 2012, 32, 42-52, DOI: 10.1111/j.1745-6592.2012.01402.x.

92 P. G. Tratnyek, A. J. Salter, J. T. Nurmi and V. Sarathy, Environmental applications of zerovalent metals: iron $v s$. zinc, in Nanoscale Materials in Chemistry: Environmental Applications, ed. L. E. Erickson, R. T. Koodali and R. M. Richards, American Chemical Society, Symposium Series, 2010, vol. 1045, pp. 165-178, DOI: $10.1021 /$ bk-20101045.ch009.

93 A. M. Garbou, C. A. Clausen and C. L. Yestrebsky, Comparative study for the removal and destruction of pentachlorophenol using activated magnesium treatment systems, Chemosphere, 2017, 166, 267-274, DOI: 10.1016/ j.chemosphere.2016.09.139.

94 G. Lee and J. Park, Reaction of zero-valent magnesium with water: potential applications in environmental remediation, Geochim. Cosmochim. Acta, 2013, 102, 162-174.

95 G. Lee, J. Park and O. R. Harvey, Reduction of Chromium(VI) mediated by zero-valent magnesium under neutral $\mathrm{pH}$ conditions, Water Res., 2013, 47, 1136-1146, DOI: 10.1016/ j.watres.2012.11.028.

96 D. M. Fan, M. J. Bradley, A. W. Hinkle, R. L. Johnson and P. G. Tratnyek, Chemical reactivity probes for assessing abiotic natural attenuation by reducing iron minerals, Environ. Sci. Technol., 2016, 50, 1868-1876, DOI: 10.1021/ acs.est.5b05800.

97 Y. T. He, J. T. Wilson, C. Su and R. T. Wilkin, Review of abiotic degradation of chlorinated solvents by reactive iron minerals in aquifers, Ground Water Monit. R., 2015, 35, 5775, DOI: 10.1111/gwmr.12111.

98 C. E. Schaefer, P. Ho, C. Gurr, E. Berns and C. Werth, Abiotic dechlorination of chlorinated ethenes in natural clayey soils: impacts of mineralogy and temperature, J. Contam. Hydrol., 2017, 206, 10-17, DOI: 10.1016/j.jconhyd.2017.09.007. 